\title{
A Comprehensive Review of Graphene-Based Anode Materials for Lithium-ion Capacitors
}

\author{
Dong Sui ${ }^{1, *,+}{ }^{+}$, Linqi $\mathrm{Si}^{2,{ }^{\dagger}}$, Changle $\mathrm{Li}^{1}$, Yanliang Yang ${ }^{1}$, Yongsheng Zhang ${ }^{2, *}$ and Weibo Yan ${ }^{3, *}$ \\ 1 Key Laboratory of Function-Oriented Porous Materials, College of Chemistry and Chemical Engineering, \\ Luoyang Normal University, Luoyang 471934, China; lichangle77@163.com (C.L.); \\ yangyli@mail.ustc.edu.cn (Y.Y.) \\ 2 School of Chemical Engineering, Zhengzhou University, Zhengzhou 450001, China; silinqi@126.com \\ 3 School of Materials Science and Engineering, Nanjing University of Posts \& Telecommunications, \\ Nanjing 210023, China \\ * Correspondence: suidonghy@mail.nankai.edu.cn (D.S.); yzhang@zzu.edu.cn (Y.Z.); \\ iamwbyan@njupt.edu.cn (W.Y.) \\ + These authors contributed equally to this work.
}

Citation: Sui, D.; Si, L.; Li, C.; Yang,

Y.; Zhang, Y.; Yan, W. A

Comprehensive Review of

Graphene-Based Anode Materials for Lithium-ion Capacitors. Chemistry 2021, 3, 1215-1246. https://doi.org/ 10.3390/chemistry3040089

Academic Editors: Xiaoyan Zhang and Raul Arenal

Received: 9 September 2021

Accepted: 12 October 2021

Published: 14 October 2021

Publisher's Note: MDPI stays neutral with regard to jurisdictional claims in published maps and institutional affiliations.

Copyright: (c) 2021 by the authors. Licensee MDPI, Basel, Switzerland. This article is an open access article distributed under the terms and conditions of the Creative Commons Attribution (CC BY) license (https:/ / creativecommons.org/licenses/by/ $4.0 /)$.

\begin{abstract}
Lithium-ion capacitors (LICs) are considered to be one of the most promising energy storage devices which have the potential of integrating high energy of lithium-ion batteries and high power and long cycling life of supercapacitors into one system. However, the current LICs could only provide high power density at the cost of low energy density due to the sluggish $\mathrm{Li}^{+}$ diffusion and/or low electrical conductivity of the anode materials. Moreover, the serious capacity and kinetics imbalances between anode and cathode result in not only inferior rate performance but also unsatisfactory cycling stability. Therefore, designing high-power and structure stable anode materials is of great significance for practical LICs. Under this circumstance, graphenebased materials have been intensively explored as anodes in LICs due to their unique structure and outstanding electrochemical properties and attractive achievements have been made. In this review, the recent progresses of graphene-based anode materials for LICs are systematically summarized. Their synthesis procedure, structure and electrochemical performance are discussed with a special focus on the role of graphene. Finally, the outlook and remaining challenges are presented with some constructive guidelines for future research.
\end{abstract}

Keywords: lithium-ion capacitors; graphene; graphene-based composites; anode materials; batterytype electrode

\section{Introduction}

Currently, lithium-ion batteries (LIBs) and supercapacitors (SCs) are regarded as two of the most important commercial electrochemical energy storage systems to power the consumer electronics and electric vehicles [1-3]. LIBs and SCs are also indispensable in the utilization of clean and renewable energy sources such as solar, wind and tide powers due to their intermittent production and uneven geographical distribution $[4,5]$. Owing to their inherently different energy storage mechanisms, LIBs and SCs exhibit greatly different electrochemical properties. For instance, LIBs have the features of high energy density, high working voltage and low self-discharge based on the Faradaic reactions, in which the $\mathrm{Li}^{+}$reversibly intercalate/de-intercalate between the cathode and anode with electrons transferred in the external circuit [6]. However, LIBs suffer from poor power density $\left(<1 \mathrm{~kW} \mathrm{~kg}^{-1}\right)$ and limited cycling life ( $<5000$ cycles) because of the sluggish $\mathrm{Li}^{+}$diffusion in the bulk electrode and structural deterioration after repeatedly charge/discharge process $[7,8]$. SCs, on the other hand, have the advantages of high power density, long cycling life, wide operation temperature and free of maintenance ascribed to the non-Faradaic electrostatic double-layer charge/discharge mechanism [9]. Unfortunately, SCs store energy via physical ions adsorption at the electrode/electrolyte interface, 
resulting in extremely low energy density $\left(<10 \mathrm{Wh} \mathrm{kg}^{-1}\right)$. Hence, developing a hybrid energy storage device which can bridge the performance gap between the LIBs and SCs is of great significance $[10,11]$.

Among the emerging various alternatives, lithium-ion capacitors (LICs), also known as lithium-ion hybrid supercapacitors, are considered to be one of the most promising energy storage systems because they possess comparable energy density to that of LIBs while keeping the high power output and long cycling life of SCs [12]. Typical LICs are composed of a battery-type electrode from LIB as the anode to provide high energy density and a capacitor-type electrode from SC as the cathode to ensure high power density and long-term durability [13]. As a hybrid device, LICs demonstrate a different energy storage mechanism, for which the lithium-ions intercalate into/de-intercalate from the battery-type anode through Faradaic reaction with anions adsorption onto/desorption from the capacitor-type cathode via a non-Faradaic process [14]. Furthermore, organic solvents containing lithium salts are generally used as electrolytes to guarantee a high working voltage because both the energy and power densities are proportional to the square of voltage. Consequently, the unique device configuration and hybrid energy storage mechanism enable LICs with the potential of overcoming the inherent drawbacks of LIBs and SCs.

Since the first protype of LICs was proposed by Amatucci and co-workers using activated carbon $(\mathrm{AC})$ as the cathode and $\mathrm{Li}_{4} \mathrm{Ti}_{5} \mathrm{O}_{12}$ (LTO) as the anode, tremendous progresses have been achieved in electrode materials, electrolytes and pre-lithium technology during the past two decades [15-17]. It should be noted that the overall electrochemical performances of LICs are crucially influenced by the specific capacity, rate capability, cycling stability and operation voltage of both the cathode and anode. For example, the capacitortype electrodes are expected to provide high power output and long lifespan. Therefore, carbon-based materials with high electrical conductivity, large specific surface area (SSA) and rich porosity are commonly adopted as the cathodes, including commercial activated carbons (ACs) [18], nanostructured carbons [19,20] biomass/polymer-derived porous carbons etc. [21-23]. As for the battery-type electrodes which provide high energy density for LICs, various anode materials used in LIBs could be applied. These materials can be roughly divided into three categories according to the lithium storage mechanisms: intercalationtype (carbon/Ti/Nb-based materials, etc.) [24-27], conversion-type (Fe/Mn/Co-based compounds, etc.) [28-30] and alloying-type (Sn/Si-based materials, etc.) [31,32] materials. More importantly, the good match in capacity and kinetics between cathode and anode also has a significant effect on the electrochemical performances of LICs. Hence, it is highly demanded to explore advanced electrode materials, especially anode materials with high rate and stable structure.

However, the electrochemical properties of the state-of-art electrode materials are still far from reaching the commercial requirements for LICs [33,34]. Taking the capacitor-type cathode as an example, the low capacity of conventional ACs is the primary cause of the limited energy density for LICs [14]. This could be mainly ascribed to the physical adsorption/desorption energy storage mechanism as well as the non-fully accessible surface area of the small and deep pores. Developing nanostructured carbon with high SSA, interconnected pores and rational pore size distribution might offer a promising solution [35]. Even so, it has become an insurmountable bottleneck to further enhance the capacity of capacitor-type electrode. Hence, it is of much practical significance to develop high-power and durable anode materials to match the cathodes. Nevertheless, the anode materials face more challenges despite many choices. First of all, the anode materials suffer from serious sluggish $\mathrm{Li}^{+}$diffusion rate, which is the main reason for the unsatisfactory power performance [13]. For non-carbon materials, the power density might be further restrained by their low electrical conductivity. Secondly, the conversion-type and alloying-type materials have a high capacity, which, however, could hardly lead to high energy density as expected. The supposed high energy density could only be realized at the cost of low power density and drops sharply when increasing the current density [19]. 
Especially, the insertion-type materials usually have relatively lower capacity and/or high lithium-ion insertion/de-insertion voltage, thus further compromising the overall energy density [36]. Thirdly, the structure degradation and huge volume fluctuation of conversion/alloying-type materials during the charge/discharge process results in poor cycling life and inferior power output [6]. Overall, the still unsatisfied electrochemical properties of the current anodes and their severe capacity and kinetics imbalance with the cathodes demand advanced battery-type materials. Therefore, to obtain anode with high power and long-term durability, it is very reasonable to design and fabricate novel nanostructured materials with fast electron transport, short lithium-ion diffusion distance and stable structure.

Graphene, a two-dimensional (2D) nanostructured carbon material, possesses many excellent properties such as high electrical conductivity, large SSA, tunable inter-layer distance, outstanding mechanical flexibility, excellent chemical stability and rich surface chemistry $[37,38]$. Benefiting from these excellent properties, graphene and its composites have already been successfully utilized in various energy storage devices, including LICs $[8,19,39,40]$. As a novel nanomaterial with so many intriguing merits, graphene provides a promising solution to the existing drawbacks of the current anode materials for LICs. As displayed in Figure 1, graphene plays a crucial role in all the battery-type electrodes of LICs. Firstly, graphene could be directly used as the high-capacity and high-rate anode because of its high theoretical capacity, excellent electron transport and adjusting layer space for fast $\mathrm{Li}^{+}$diffusion [41,42]. Secondly, graphene could increase the overall electrical conductivity and enhance the reversible capacity when forming composites with non-carbon materials [43]. Lastly, the unique 2D structure with outstanding flexibility and mechanical stability makes graphene an ideal substrate to buffer the huge volume change and prevent particle growth of conversion/alloying-type materials [44]. Obviously, graphene could significantly improve the performance of battery-type electrodes for LICs by serving either as extraordinary active materials or as flexible and conductive 2D support. With the increasing interest in this booming field and still big challenges existing in the commercialization of LICs, a systematic overview of graphene-based anodes is urgently needed for both academic and industrial communities. Hence, in this review, we comprehensively summarize the recent achievements of graphene-based anode materials in LICs. The discussions cover the fabrication process, morphology, structure, electrochemical performance of the electrode materials and also pays a special focus on the important effect of graphene. In the end, an outlook is presented to highlight the future challenges and possible research directions. We hope this review will offer some useful guidelines to develop advanced graphene-based anode materials for high-performance LICs. 


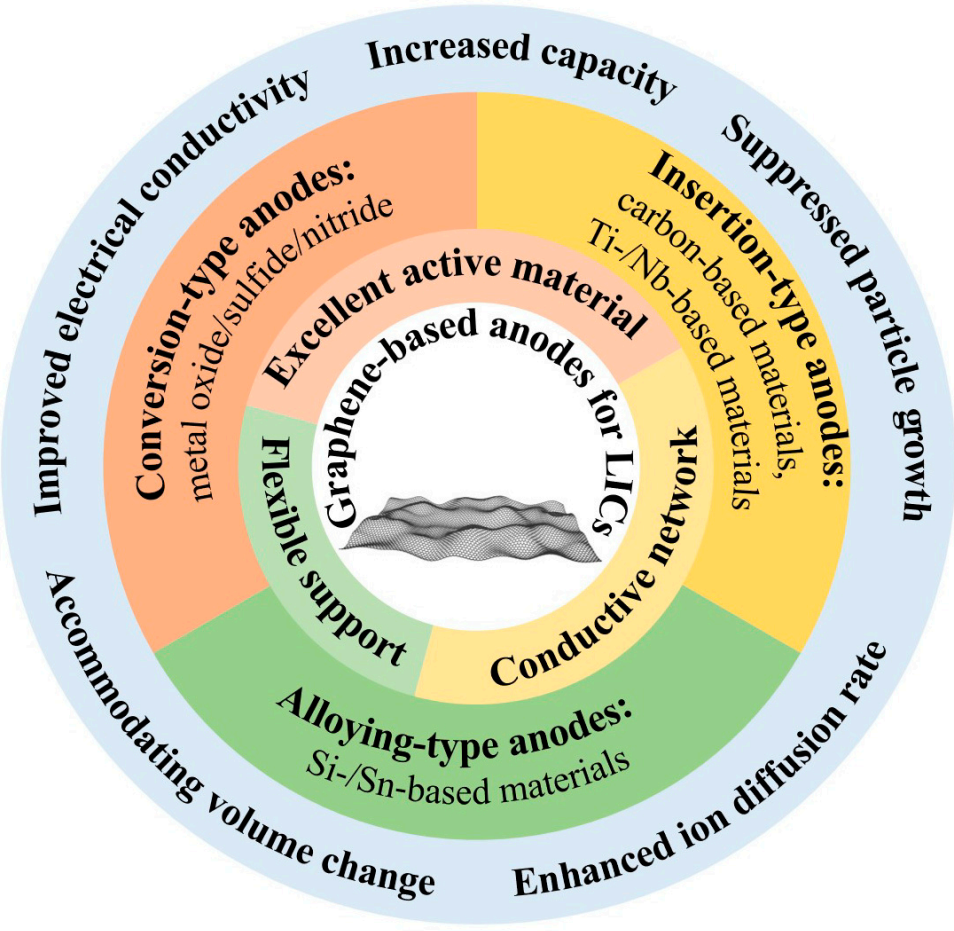

Figure 1. Graphene-based anode materials for LICs.

\section{Graphene-Based Carbonaceous Anode Materials}

Carbon-based materials have been widely applied in commercial energy storage devices (such as graphite in LIBs and AC in SCs) because of their inherently high electrical conductivity, low cost, mature production process and abundant resources. In the early stage of LICs, graphite has been used as the anode [45]. However, its practical application has been inhibited by the inferior power performance, which could be ascribed to the small inter-layer distance of graphite, high crystallinity and anisotropy [46]. Hard carbons have also been adopted thanks to their improved rate capability compared with graphite [47]. The acceptable rate performance can be ascribed to the enlarged layer distance and the isotropic structure [48]. However, the limited capacity, large irreversible capacity and hysteresis in the voltage profile have seriously restricted their further applications [49]. Under this circumstance, graphene-based carbonaceous materials are emerging as attractive anodes for LICs.

\subsection{Graphene as Anode Material}

According to the theoretical calculation, graphene has a specific capacity of $744 \mathrm{mAh} \mathrm{g}^{-1}$ based on $\mathrm{Li}_{2} \mathrm{C}_{6}$ since both sides can host lithium-ions, which is twice and over 4 times higher than that of graphite (372 $\mathrm{mAh} \mathrm{g}^{-1}$ based on $\left.\mathrm{LiC}_{6}\right)$ and LTO $\left(175 \mathrm{mAh} \mathrm{g}^{-1}\right)$, respectively $[42,50]$. Moreover, the in-plane defects and exposed sheet edges of graphene can offer more active sites for Li ions, which leads to a higher capacity than the theoretical value [51]. Previous reports have confirmed that pristine graphene and heteroatom doped graphene showed large reversible capacity and excellent rate performance in LIBs [50,52], making graphene an even more attractive alternative as battery-type anode for LICs. For example, Ren et al. proposed pre-lithiated graphene nanosheets (GNSs) as a battery-type electrode in LICs by pairing with AC [46]. The pre-lithiated graphene presented a reversible capacity of $760 \mathrm{mAh} \mathrm{g}^{-1}$, over 2 times higher than that of graphite. LICs based on this anode delivered a capacitance of $168.5 \mathrm{~F} \mathrm{~g}^{-1}$ under the working voltage of $2.0-4.0 \mathrm{~V}$ with a maximum energy and power densities of $61.7 \mathrm{Wh} \mathrm{kg}^{-1}$ and $222.2 \mathrm{~W} \mathrm{~kg}^{-1}$, respectively. Although pre-lithiated GNSs-based LICs showed superior performances over pre-lithiated graphite-based ones, their rate results are still unsatisfactory. To further improve the power 
performance, developing graphene with enlarged interlayer distance, porous structure or heteroatom doping is commonly adopted.

Designing graphene with large inter-layer space is an effective method to facilitate $\mathrm{Li}^{+}$storage and diffusion, which thus improves the energy and power performances. For instance, the work by Zhang et al. reported a flash-reduced graphene oxide (FRGO) as the anode for LICs [14]. Free-standing GO film was firstly prepared by vacuum filtration and then reduced with a digital camera photoflash to obtain FRGO. After photothermal reduction, the grey and smooth surface of GO film became black and rough due to the remove of oxygen-containing groups (Figure 2a). As shown in Figure $2 b$ of the side view image of a partially reduced GO film, the thickness of the reduced part (left side) is clearly increased compared with the unreduced part (right side). The pressure between the GO sheets which was generated by the rapid degassing accounts for the phenomenon. This could be further verified by the cross-sectional SEM image in Figure $2 \mathrm{c}$ which demonstrates FRGO has a quite expanded structure with large voids and pathways between the highly curved graphene sheets. The loose structure with open pores is considered to raise the lithium-ions diffusion between the graphene sheets and thus achieve a fast charge/discharge rate. As expected, FRGO anode exhibited outstanding electrochemical results, including a high capacity of over $660 \mathrm{mAh} \mathrm{g}^{-1}$ at $0.4 \mathrm{C}$, an excellent rate capability of $220 \mathrm{mAh} \mathrm{g}^{-1}$ at $10 \mathrm{C}$ and about $85 \%$ retention after 5000 cycles (Figure $2 \mathrm{~d}, \mathrm{e}$ ). The superior results are attributed to the good conductivity, large SSA and open-pore structure of FRGO as well as the unique lithium storage mechanism of graphene (both sides of graphene sheet could store lithiumions). As a result, LICs fabricated with FRGO anode and porous three-dimensional (3D) graphene-based cathode display high energy densities of $148.3-71.5 \mathrm{Wh} \mathrm{kg}^{-1}$ with the power densities ranging from 141 to $7800 \mathrm{~W} \mathrm{~kg}^{-1}$. Later, Ahn et al. fabricated a highly oriented rGO sponge (HOG) by thermal annealing the freeze-dried GO foam [53]. The HOG has a well-oriented and 3D porous structure formed through edge-by-edge connecting of graphene sheets, which is beneficial to $\mathrm{Li}^{+}$storage and diffusion and in turn improve the energy and power densities of the obtained LICs. Therefore, the full-cell devices constructing with AC cathode and HOG-Li anode displayed a remarkably high energy density of 231.7 and $131.9 \mathrm{Wh} \mathrm{kg}^{-1}$ at 0.057 and $2.8 \mathrm{~kW} \mathrm{~kg}^{-1}$, respectively. From the above description, elaborate engineering of inter-layer space or microstructure could largely increase the capacity and rate of graphene-based anode because of their large SSA, continuous 3D electron transport network and interconnected pores for rapid ion diffusion. Moreover, the technique can be easily extended to other metal-ion batteries or capacitors (such as $\mathrm{Na}-/ \mathrm{K}-/ \mathrm{Zn}$-based energy storage devices).

Materials with high SSA and rich porosity are expected to achieve outstanding capacity and rate performances through increasing lithium-ion storage sites and enhancing electrolyte permeation and diffusion. Thus, 3D porous graphene is generally prepared with template. The work by Sha et al. designed a 3D bi-functional modular graphene network (3D bmG) synthesized by using $\mathrm{Ni}$ metal powder assisted $\mathrm{NaCl}$ template method for all-carbon LICs [54]. Specially, the 3D graphene catalyzed by Ni powder with high crystallization degree (bmG-n) is supposed to improve conductivity, reduce irreversible capacity and provide high platform capacity and the 3D graphene grown on $\mathrm{NaCl}$ crystals with low crystallization degree (bmG-s) is helpful to provide high capacity and rate performance because of more defects and active sites. With the optimal conditions, the obtained free-standing 3D bmG-40 has a 3D interconnected porous structure and is composed of two kinds of modules with two different functions (Figure $3 a, b$ ). As clearly displayed in Figure $3 \mathrm{c}, 3 \mathrm{D}$ bmG-40 possesses the highest SSA, largest pore volume and acceptable conductivity. As the anode, 3D bmG-40 showed a reversible capacity of around $700 \mathrm{mAh} \mathrm{g}^{-1}$ with a platform below $0.2 \mathrm{~V}$, illustrating the advantages of bi-functional modular materials. Further, 3D bmG-40 also had the best overall performances in terms of the rate capability and cycling stability (Figure 3d,e). In accordance with the expectation, the full LIC with 3D bmG-40 as both the anode and cathode presented a large working voltage of up to $4.5 \mathrm{~V}$, an extremely high energy density of $278 \mathrm{Wh} \mathrm{kg}^{-1}$ (at $405 \mathrm{~W} \mathrm{~kg}^{-1}$ ) and a high-power density 
of $16.2 \mathrm{~kW} \mathrm{~kg}^{-1}$ (at $52.2 \mathrm{Wh} \mathrm{kg}^{-1}$ ) as well as long cycling life with capacity retention of $88.57 \%$ after 3000 cycles (Figure $3 f, g$ ).
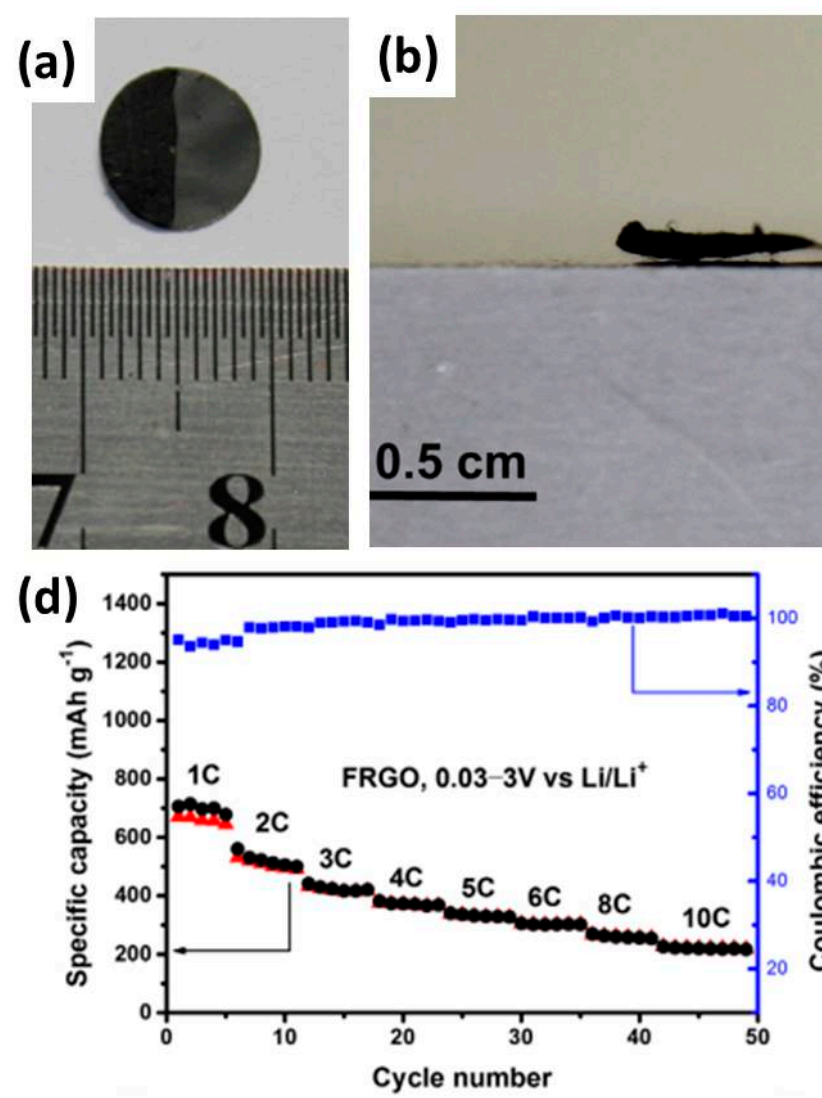

(b)

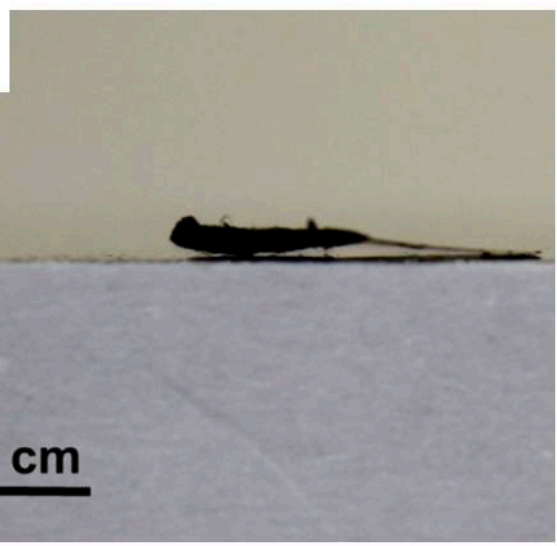

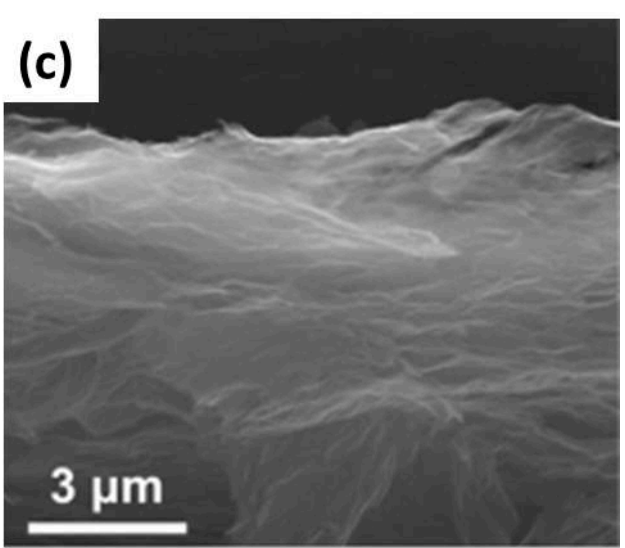

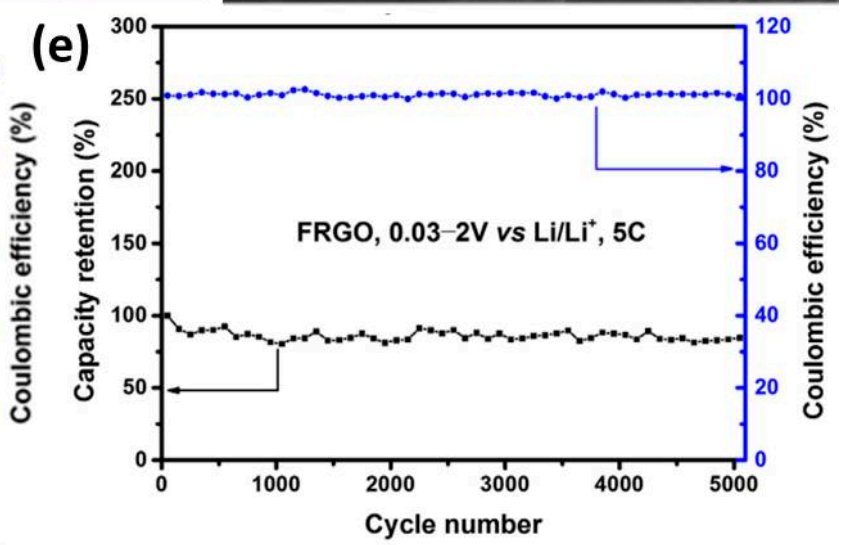

Figure 2. Optical images of (a) top view and (b) side view of partially reduced GO film disc; (c) SEM image of FRGO film; (d) rate performance and (e) cycling stability of FRGO. Reproduced with permission from [14]. Copyright 2015, Elsevier.

Nanostructured $\mathrm{MgO}$ is another commonly used hard template to prepare porous materials because of its structural, compositional and thermal stability. In addition, heteroatom doping is a valid strategy to improve the capacity and rate performance of carbon materials due to more active sites for ion adsorption/rapid pseudocapacitive reaction, good wettability, enlarged inter-layer spacing and increased electrical conductivity $[55,56]$. Ma's group designed a porous graphene material by self-propagating high-temperature magnesiothermic reaction of $\mathrm{CO}_{2}$ and $\mathrm{Mg}$ with $\mathrm{MgO}$ as the hard template (SHSG) [57]. The as-obtained product exhibits high electrical conductivity, large SSA, abundant mesopores and high $\mathrm{C} / \mathrm{O}$ atomic ratio, which improved the capacity and rate capability compared with conventional graphite. As an anode, a specific capacity of $865 \mathrm{mAh} \mathrm{g}^{-1}$ at $0.4 \mathrm{C}$ was achieved for SHSG, which still retains $333 \mathrm{mAh} \mathrm{g}^{-1}$ at $10 \mathrm{C}$ [58]. By pairing it with a high-capacity $\mathrm{N}$-doped hierarchical carbon nanolayers-based cathode, the obtained LICs deliver a high energy density of $146 \mathrm{Wh} \mathrm{kg}^{-1}$, an ultrahigh power density of $52 \mathrm{~kW} \mathrm{~kg}^{-1}$ and an extremely long cycling life of 40,000 cycles with capacity retention of $91 \%$. Later, they reported a nitrogen-enriched graphene framework (NGF) prepared with a similar method except for introducing melamine as the precursor and $\mathrm{N}$ dopant (Figure 4a) [59]. The morphology and crystallinity of NGF are largely influenced by the added melamine and could be regulated by its amount. For example, the optimal NGF-2 is composed of a continuously cross-linked and porous graphene framework with well-defined edges, plenty of open pores between adjacent sheets and abundant on-plane ripples and crumples (Figure $4 b, c)$. Thanks to the novel structure and N doping, NGF-2 displayed a reversible capacity of 1350 and $776 \mathrm{mAh} \mathrm{g}^{-1}$ at 0.2 and $3 \mathrm{~A} \mathrm{~g} \mathrm{~g}^{-1}$, respectively, which are better than the controlled samples (Figure 4d). Moreover, NGF-2 maintained a capacity of $825 \mathrm{mAh} \mathrm{g}^{-1}$ at $2 \mathrm{~A} \mathrm{~g}^{-1}$ after 300 cy- 
cles with an outstanding retention of $97.4 \%$ (Figure 4e). Based on the kinetic analysis, NGF-2 had a fast surface-governed kinetics with capacitive capacity contributing to the main $\mathrm{Li}^{+}$ storage, especially at high scan rates (Figure 4f). The excellent electrochemical properties of NGF-2 could be largely attributed to the decreased contact inter-layer resistance due to the cross-linked framework, sufficient electrode/electrolyte interface and rapid charge-transfer reaction due to rich porosity, increased active sites for ions adsorption and improved electrolyte wettability and diffusion because of $\mathrm{N}$ doping (Figure $4 \mathrm{~g}$ ). Consequently, the LICs based on NGF-2 anode and NGF cathode delivered a high energy density of $151 \mathrm{Wh} \mathrm{kg}^{-1}$, an ultrahigh power density of $49 \mathrm{~kW} \mathrm{~kg}^{-1}$ (at $86 \mathrm{Wh} \mathrm{kg}^{-1}$ ) and a good cycling retention of $87 \%$ after 10,000 cycles. From the above description, it could be easily concluded that the high conductivity, abundant active sites and rapid ion diffusion rate of the doped porous graphene anode accounts for the enhanced performance.
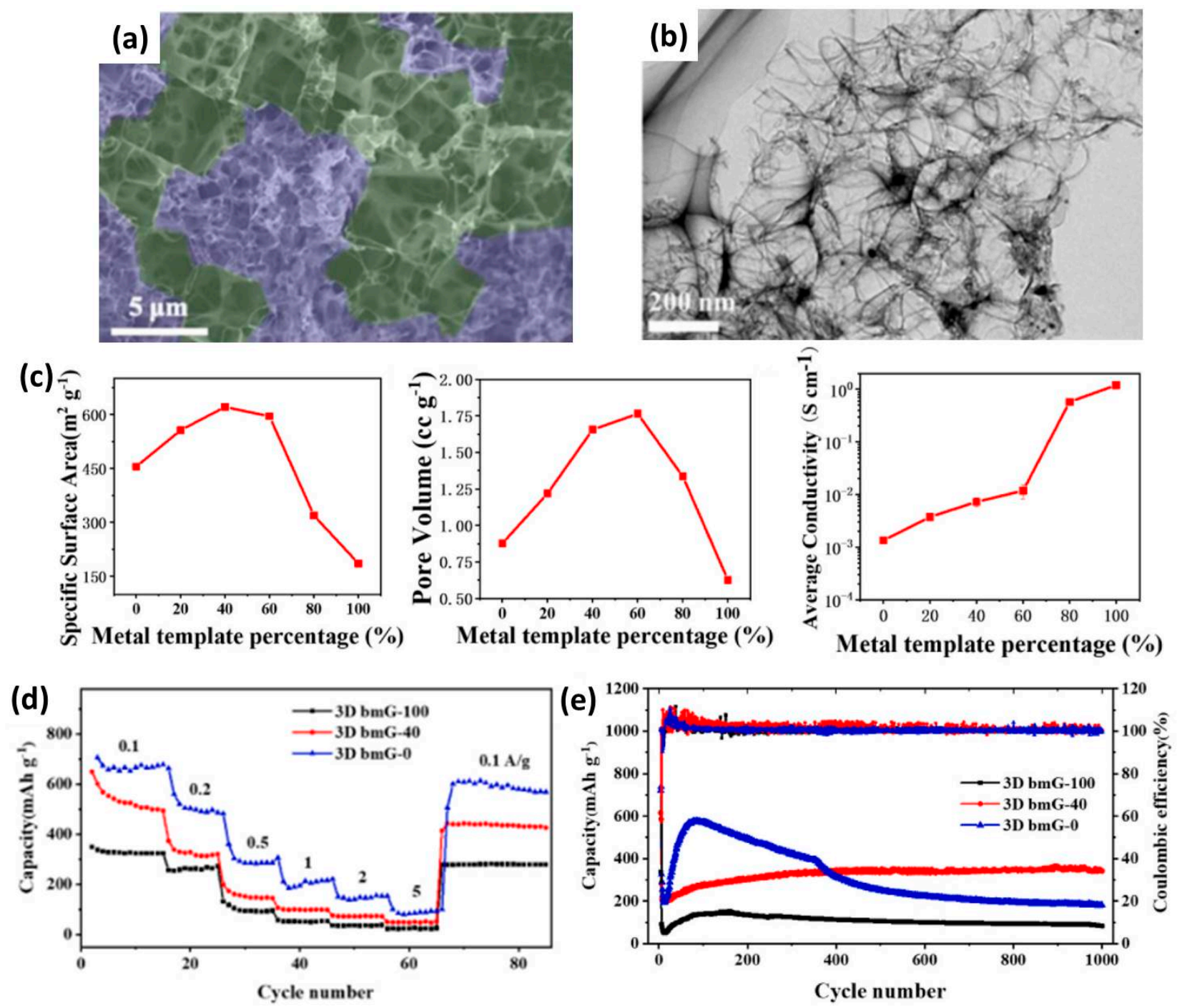

Figure 3. Conts. 
(f)

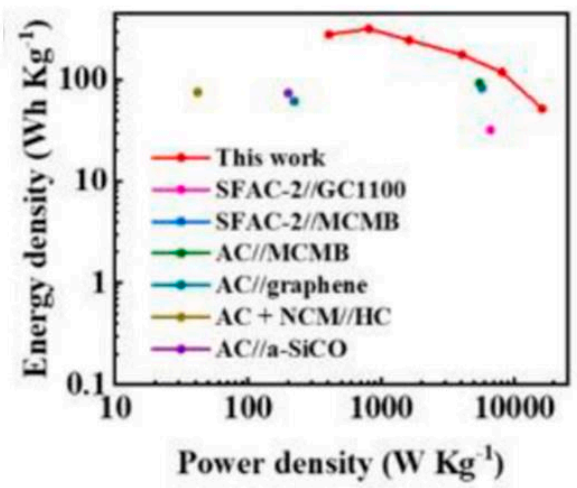

(g)

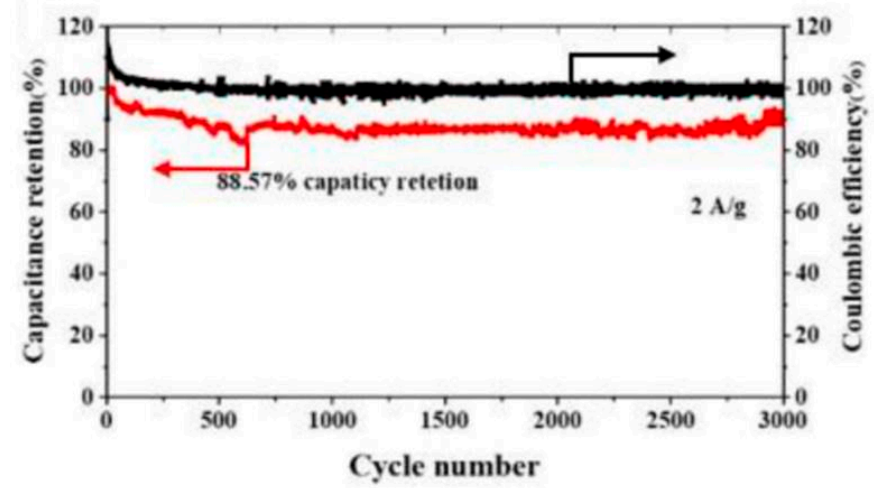

Figure 3. (a) SEM and (b) TEM images of 3D bmG-40 (in SEM, bmG-s part is marked in green, and the bmG-n part is marked in blue); (c) the specific surface area, pore volume and electrical conductivity of 3D bmG with different nickel templates percentages; (d) rate capability and (e) cycling stability of all samples; (f) Ragone plots and (g) cycling performance of bmG-40//bmG-40 LIC. Reproduced with permission from [54]. Copyright 2021, Elsevier.
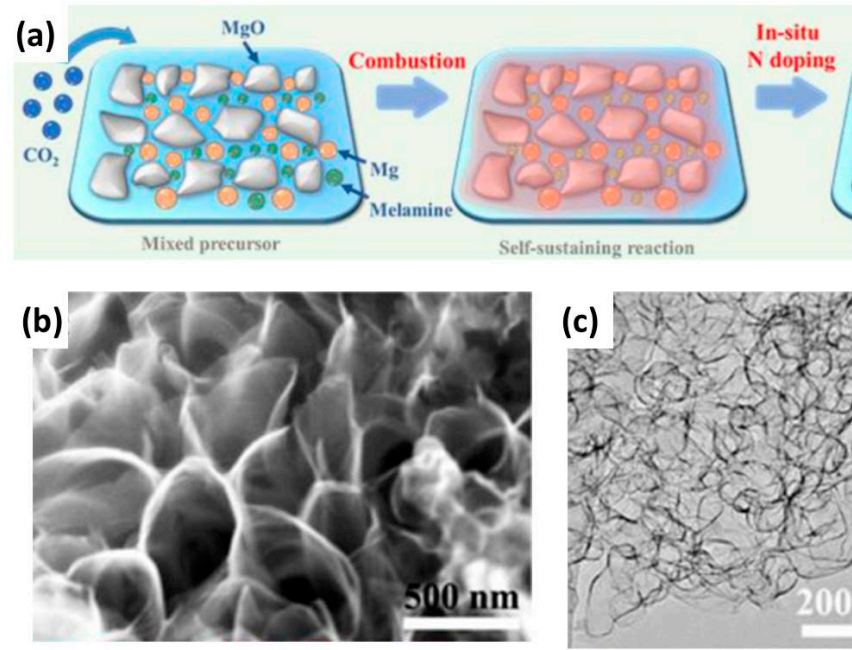

(e)

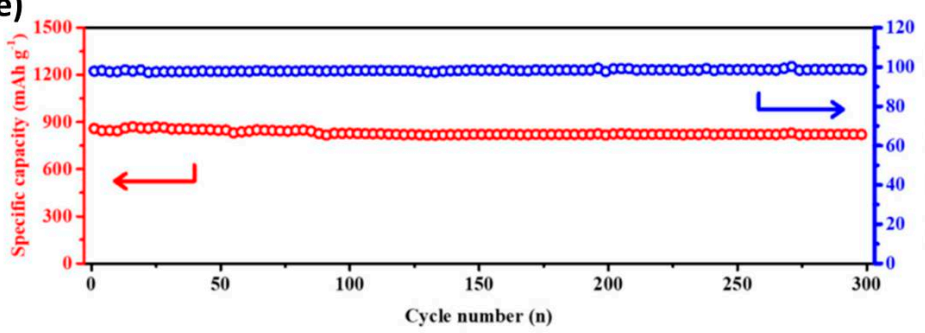

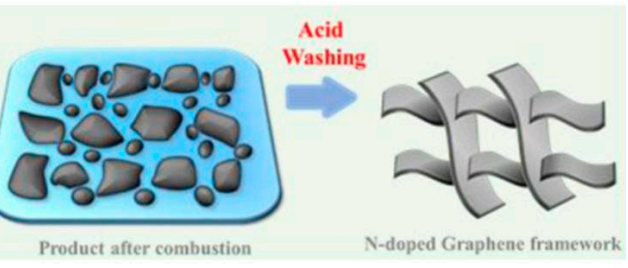

(d)
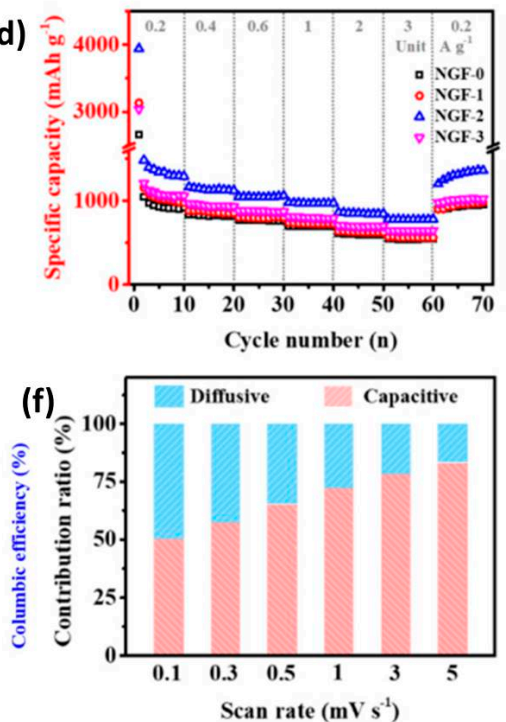

(g)

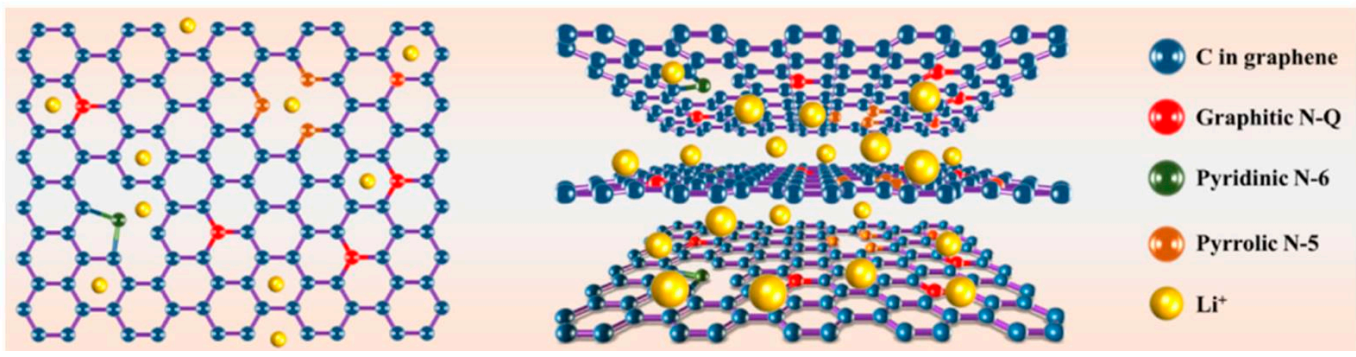

Figure 4. (a) Schematic illustration of the synthesis of the N-doped graphene framework via combustion synthesis; (b) SEM and (c) TEM images of NGF-2; (d) rate capability of different NGF materials; (e) cyclic stability of NGF-2 at $2 \mathrm{~A} \mathrm{~g} \mathrm{~g}^{-1}$; (f) CV curve of NGF-2 at $1 \mathrm{mV} \mathrm{s}^{-1}$ and the shadowed area represented the capacitive contribution; (g) schematic illustration showing the initial stage of capacitive and bulk storage in NGF-2. Reproduced with permission from [59]. Copyright 2021, Springer. 
Through rationally designing the inter-layer distance, porosity and chemical composition, graphene can be an excellent anode candidate by directly used as active material. However, it is still a big challenge to prepare graphene at a commercially acceptable cost. Moreover, the high capacity and high rate is commonly obtained with porous graphene, which usually results in large irreversible capacity, low Coulomb efficiency as well as inferior volumetric energy density. Thus, so far, one promising solution is to fabricate graphene-based composites.

\subsection{Graphene-Modified Carbonaceous Composites as Anode Materials}

The practical utilization of graphene is impeded by the high cost, sophisticated preparation process and severe aggregation. Hence, introducing other carbonaceous materials into graphene to form composites could not only reduce the overall cost and inhibit the restacking but also keep the inherent properties of graphene [60]. Yang et al. prepared polydopamine-graphene composite (PDA-GN) by depositing redox active polymer onto the surface of reduced GO and used it as anode in LICs [61]. The PDA-GN had a wrinkled morphology and abundant interconnected macropores with no obvious aggregation (Figure 5a). The TEM images clearly showed that PDA-GN has a 2D sandwich structure and PDA was evenly coated on the graphene nanosheets (Figure $5 b, c$ ). As displayed in Figure 5d, PDA-GN presents a reversible capacity of 1150 and $371 \mathrm{mAh} \mathrm{g}^{-1}$ at 0.05 and $5 \mathrm{~A} \mathrm{~g}^{-1}$, respectively. The 2D morphology, numerous active sites and porous structure of the composite coupled with high electrical conductivity of graphene are beneficial to the remarkable electrochemical performance. Consequently, dual-graphene LICs fabricated with PDA-GN anode and porous graphene cathode achieved a high energy density of $135.6 \mathrm{Wh} \mathrm{kg}^{-1}$ and a high-power density of $21.0 \mathrm{~kW} \mathrm{~kg}^{-1}$ (Figure 5e). More importantly, the devices could deliver an energy density of $76.4 \mathrm{Wh} \mathrm{kg}^{-1}$ at a low temperature of $-20{ }^{\circ} \mathrm{C}$. Recently, Sui et al. reported a graphene-modified carbon (GC) which was facilely prepared by annealing graphene/phenol formaldehyde resin (PF) composite [62]. During the hydrothermal reaction, PF was induced to form on the surface of graphene oxide. Thus, the as-prepared sample presented a thin layered structure with some micropores and defects after thermal treatment. Benefiting from unique nanostructure, the obtained PF-derived carbon demonstrated a high reversible capacity of over 530 and $210 \mathrm{mAh} \mathrm{g}^{-1}$ at $0.1 \mathrm{~A} \mathrm{~g}^{-1}$ and $5.0 \mathrm{~A} \mathrm{~g}^{-1}$, respectively. With GC as the anode and graphene-enhanced porous carbon as the cathode, the all-graphene LICs were assembled and exhibit a maximum energy and power densities of $142.9 \mathrm{Wh} \mathrm{kg}^{-1}$ and $12.1 \mathrm{~kW} \mathrm{~kg}^{-1}$. Besides, other graphene modified carbon materials as anodes have been reported, including graphene oxide (rGO) coated melamine foam or GO/poly(aniline) aerogel derived doped carbons [63,64], biomass waste derived hard carbon/graphene composites [65,66], and graphene/soft carbon [67].

With large aspect ratio and high conductivity, carbon nanotube (CNT) could serve as an outstanding spacer to inhibit graphene restacking [68]. For example, Sun et al. reported a LIC device using single walled carbon nanotube and graphene (SG) composite as both the cathode and anode [69]. Thanks to the introduction of CNT, the restacking of graphene nanosheets was effectively suppressed and the obtained 3D composite showed high electrical conductivity and large SSA with more intra-pores compared with pristine chemically reduced graphene. As an anode, pre-lithiated SG delivered a reversible capacity of $562 \mathrm{mAh} \mathrm{g}^{-1}$ at $50 \mathrm{~mA} \mathrm{~g}^{-1}$. The outstanding performance could be attributed to larger inter-layer space, more structural defects and enhanced accessibility for $\mathrm{Li}^{+}$of the $3 \mathrm{D}$ SG composite. Similarly, Adelowo et al. demonstrated an all-graphene-based LIC with reduced graphene oxide-carbon nanotubes (rGO-CNT) electrodes [70]. rGO-CNT showed a reversible capacity of $990 \mathrm{mAh} \mathrm{g}^{-1}$ at $0.1 \mathrm{~A} \mathrm{~g}^{-1}$, which still keeps $598 \mathrm{mAh} \mathrm{g}^{-1}$ at a high current density of $2 \mathrm{~A} \mathrm{~g}^{-1}$. These values are significantly higher than those for both $\mathrm{rGO}$ and CNT, indicating an improved electron/ionic conductivity for the rGO-CNT electrode. The LICs displayed high energy and power densities of $114.5 \mathrm{Wh} \mathrm{kg}^{-1}$ and $2.57 \mathrm{~kW} \mathrm{~kg}^{-1}$, respectively. Based on the above discussion, an obvious conclusion could be drawn that high-capacity and high-rate 3D graphene-based anode could be achieved by forming 
composites with other carbon materials while the issues of high cost and agglomeration of graphene could be overcome.
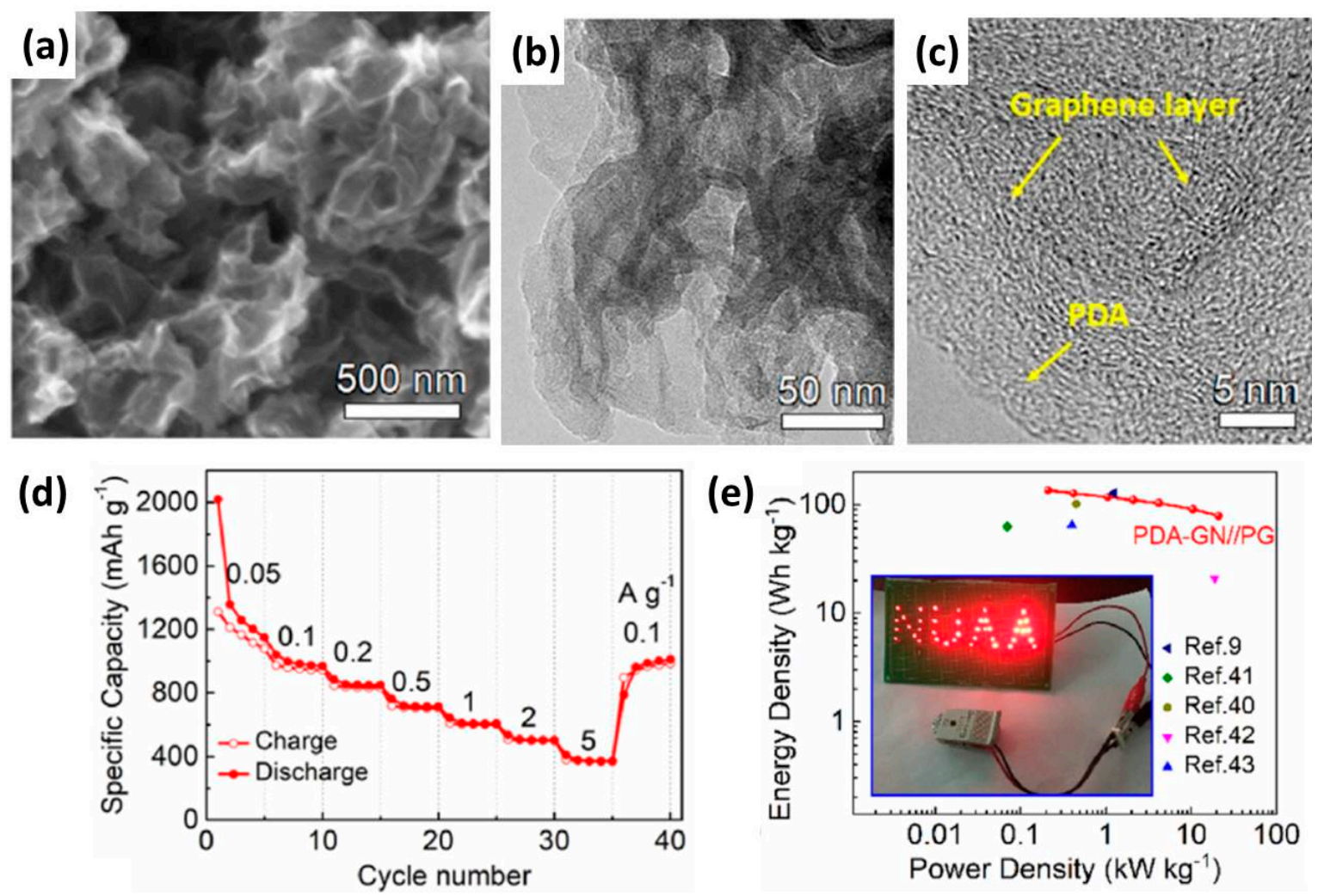

Figure 5. SEM (a), TEM (b,c) of the PDA-GN composite; (d) rate performance of PDA-GN anode; (e) Ragone plot of PDA-GN//PG LIC. Reproduced with permission from [61]. Copyright 2020, Elsevier.

In conclusion, graphene can be directly used as active material or as a nanostructured additive to modify other carbonaceous materials in LICs. For easy comparison, the electrochemical performances of the graphene-based anode materials and their full cells are summarized in Table 1. As we can see from these results, LICs with graphene-based carbonaceous anodes exhibit outstanding electrochemical properties because high conductivity, tunable interlayer space and controllable microstructure and composition lead to high capacity and excellent rate.

\section{Graphene-Based Hybrid Anode Materials}

Besides the carbonaceous anodes, other battery-type materials with intercalation/ conversion/alloying-based mechanisms are also drawing tremendous attention in LICs. However, these materials suffer from low electrical conductivity and/or huge volume variation during the charge/discharge process, which usually results in limited power density and poor cycling performance. Fortunately, graphene can be used as an outstanding substrate or building unite to load the intercalation/conversion/alloying-type compounds and form hybrid anode materials, which could form a highly conductive network, suppress the large volume change and mitigate the restacking problem of graphene sheets. Therefore, it is of great significance to investigate the electrochemical properties of these graphenebased hybrid materials in LICs and the role of graphene in them. 
Table 1. Graphene-based carbonaceous anode materials and their LICs performance.

\begin{tabular}{|c|c|c|c|c|c|c|c|}
\hline $\begin{array}{c}\text { Anode } \\
\text { Materials }\end{array}$ & $\begin{array}{c}\text { Capacity of } \\
\text { Anode (mAh g-1) }\end{array}$ & $\begin{array}{l}\text { Area Loading } \\
\text { Mass }\left(\mathrm{mg} \mathrm{cm}^{-2}\right)\end{array}$ & $\begin{array}{l}\text { Cell Voltage } \\
\text { (V) }\end{array}$ & $\begin{array}{l}\text { Maximum } \\
\text { Energy Density } \\
\left(W^{-1} \mathbf{k g}^{-1}\right)\end{array}$ & $\begin{array}{c}\text { Maximum } \\
\text { Power Density } \\
\left(\mathrm{kW} \mathrm{kg}^{-1}\right)\end{array}$ & Cycling Stability & Reference \\
\hline FRGO & 660 & $\sim 1$ & $0-4.2$ & 148.3 & 7.8 & $\sim 80 \%$ after 3000 & [14] \\
\hline HOG & 1019 & 5 & $2-4.2$ & 231.7 & 2.8 & $84.2 \%$ after 1000 & [53] \\
\hline SHSG & 854 & 1.5 & $2-4.5$ & 146 & 52 & $91 \%$ after 40,000 & [58] \\
\hline $\begin{array}{l}\mathrm{N}-\mathrm{rGO} \\
\text { aerogel }\end{array}$ & 1444.04 & $\sim 0.82$ & $2-4$ & 170.28 & 25.75 & $\sim 100 \%$ after 3000 & [71] \\
\hline N-DGA & 1387 & I & $2-4$ & 39 & 1.2 & $71 \%$ after 2000 & [56] \\
\hline NGF-2 & 1361 & 2 & $1-4$ & 151 & 49 & $87 \%$ after 10,000 & [59] \\
\hline N-GS & 395 & $1-1.5$ & $0-4.5$ & 187.9 & 11.25 & $93.5 \%$ after 3000 & [64] \\
\hline $3 \mathrm{D}$ bmG & $\sim 780$ & I & $0-4.5$ & 278 & 16.2 & $88.57 \%$ after 3000 & [54] \\
\hline GC & 530 & $1-1.5$ & $0-4.2$ & 142.9 & 12.1 & $88 \%$ after 5000 & [62] \\
\hline G/SC & 360 & $\sim 1$ & $1-4.1$ & 151 & 18.9 & $93.8 \%$ after 10,000 & [67] \\
\hline HC-rGO & 450 & $\sim 1$ & $1.5-4.2$ & 200 & 10 & $88 \%$ after 10,000 & [66] \\
\hline Li-SG & 500 & 1 & $0-4.1$ & 222 & / & $58 \%$ after 5000 & [69] \\
\hline PDA-GN & 1150 & 0.5 & $0.01-4.2$ & 135.6 & 21.0 & $98 \%$ after 3000 & [61] \\
\hline
\end{tabular}

\subsection{Graphene/Intercalation-Type Anode Materials}

Compared with carbonaceous anodes, intercalation-type materials such as $\mathrm{Ti} / \mathrm{Nb}-$ based compounds have the features of relatively higher $\mathrm{Li}^{+}$diffusion rate and smaller volume change. These excellent properties render them intriguing anode candidates with high power and long-term durability. However, these materials usually suffer from low electrical conductivity and slow bulk ion transport, seriously limiting their power density. Moreover, their relatively low specific capacity and high working potential lead to unsatisfactory energy density. As a result, several strategies are commonly adopted to tackle these shortcomings, including fabricating composites with highly conductive material (such as graphene), rationally regulating the porosity, and carefully designing the micro/nanostructure.

\subsubsection{Graphene/Ti-Based Materials}

Among the Ti-based materials, LTO is one of the most promising anodes due to the following advantages: (1) excellent safety and high coulombic efficiency (close to $100 \%$ ) without forming lithium dendrite and solid-electrolyte interface (SEI) because of the high operating potential of $1.5 \mathrm{~V} \mathrm{vs} . \mathrm{Li} / \mathrm{Li}^{+}$; (2) long cycling performance because of near zero-strain during the charge/discharge process and (3) stable spinel structure with $3 \mathrm{D} \mathrm{Li}^{+}$diffusion channels [72]. Since the pioneering work by Amatucci and co-workers, LTO has been widely adopted as anode for LICs $[15,26,36,73]$. However, the still inferior rate performances derived from low $\mathrm{Li}^{+}$diffusion coefficient $\left(<10^{-6} \mathrm{~cm}^{-2} \mathrm{~s}^{-1}\right)$ and poor electrical conductivity $\left(2.65 \times 10^{-7} \mathrm{~S} \mathrm{~cm}^{-1}\right)$ inhibit their application in fields requiring high power output [74]. To overcome this obstacle, incorporating nanosized LTO into graphene-based conductive materials is a highly feasible method and high-performance LTO/graphene composites can be achieved by adjusting the synthesis parameters and the amount of graphene $[75,76]$.

For example, Leng et al. reported an advanced all-graphene-based LIC using grapheneinserted LTO composite (G-LTO) as the anode and graphene/sucrose derived 3D porous material as the cathode [43]. As shown in Figure 6a, G-LTO was facilely prepared through a solvothermal reaction of ball-milled LTO cluster and GO sheets followed by heat treatment. Obviously, nanosized LTO particles are well dispersed among the crumpled graphene network and evenly covered by the graphene sheets (Figure $6 b, c)$. Benefiting from the graphene modification and the synergistic effect between LTO and graphene, the opti- 
mized G-LTO with only $3.6 \mathrm{wt} \%$ of graphene delivered a capacity of $207 \mathrm{mAh} \mathrm{g}^{-1}$ and $176 \mathrm{mAh} \mathrm{g}^{-1}$ at $0.3 \mathrm{C}$ and $1 \mathrm{C}$, respectively (Figure $6 \mathrm{~d}$ ). More importantly, G-LTO also exhibited excellent rate capability compared with pure LTO (Figure 6e). The outstanding electrochemical performance of graphene/LTO nanocomposite anode could be attributed to: (1) the enhanced electrical conductivity because of the 3D conductive graphene network; (2) fast ion pathways due to graphene sheets hindering LTO agglomeration; and (3) the extra capacity contribution from the graphene spacer. The full cell delivered a high energy density of $95 \mathrm{Wh} \mathrm{kg}^{-1}$ at $0.4 \mathrm{C}$ and still retained $32 \mathrm{Wh} \mathrm{kg}^{-1}$ at an ultrahigh rate of up to 100 C. Later, a work by Wang et al. fabricated a composite composed of nanosized LTO and graphene nanosheets using a novel atomic layer deposition (ALD) seeded process in combination with hydrothermal lithiation and thermal treatment (Figure 6f) [77]. As presented in the SEM and TEM images of Figure $6 \mathrm{~g}, \mathrm{~h}$ for the optimized sample, LTO nanoparticles with an average size of $21.0 \mathrm{~nm}$ were homogenously anchored on the surface of wrinkled graphene without obvious aggregation. Owing to the efficiently conductive network of graphene and the strictly restrained LTO particle size by the ALD seeded route, a facile electron transport network and a short lithium-ion diffusion path were achieved. The integrated effects of nanosized LTO and graphene endowed the as-obtained composite with a high reversible capacity of $212.9 \mathrm{mAh} \mathrm{g}^{-1}$ at $0.5 \mathrm{C}$, which still kept $120.8 \mathrm{mAh} \mathrm{g}^{-1}$ at an extremely high rate of $100 \mathrm{C}$ (Figure 6i). As might have been expected, the LICs based on the LTO/graphene anode and commercial AC cathode achieved a maximum energy and power densities of $52 \mathrm{Wh} \mathrm{kg}^{-1}$ and $57.6 \mathrm{~kW} \mathrm{~kg}^{-1}$, respectively. Furthermore, a stable cycling was achieved with a capacity retention of $97 \%$ after 2000 cycles at a high current density of $25 \mathrm{~A} \mathrm{~g}^{-1}$.

Porous graphene is also adopted to further enhance the power output of LTO by improving the $\mathrm{Li}^{+}$diffusion rate. For example, Jeong et al. applied holey graphene (HG) with nanosized pores as building blocks to prepare spherical HG-based electrode materials [78]. Specially, a spherical holey graphene supported LTO (LTO/HG) anode was designed for LICs by spray-drying flat $\mathrm{HG}$ and $\mathrm{Ti} / \mathrm{Li}$ precursors followed by thermal annealing. As shown in Figure 7a, the spherical LTO/HG composite with a size of 2-3 $\mu \mathrm{m}$ was compactly assembled and the LTO particles were well wrapped by HG, predicting that the conductivity could be largely improved. As further revealed by $\mathrm{N}_{2}$ adsorption/desorption isotherms (Figure $7 \mathrm{~b}$ ), smaller mesopores ( $4-8 \mathrm{~nm}$ ) were also observed for the spherical LTO/HG sample owing to the in-plane holes of HG. The superiority of the novel structure for the spherical LTO/HG could be verified by the rate capability. As displayed in Figure 7c, the spherical LTO/HG and LTO/rGO have a comparable capacity at low current density $\left(\sim 170 \mathrm{mAh} \mathrm{g}^{-1}\right.$ at $\left.0.1 \mathrm{~A} \mathrm{~g}^{-1}\right)$. However, the capacity of spherical LTO/rGO drops sharply with increasing the rate and only $3.3 \%$ remained at $30 \mathrm{~A} \mathrm{~g}^{-1}$ while spherical LTO/HG composite showed capacity retention of $68.6 \%$ and $49.0 \%$ at $30 \mathrm{~A} \mathrm{~g}^{-1}$ and $50 \mathrm{~A} \mathrm{~g}^{-1}$, respectively. As expected, LIC assembled with spherical LTO/HG as the anode and HG as the cathode delivered a maximum energy density of $117.3 \mathrm{Wh} \mathrm{kg}^{-1}$ (at $0.1 \mathrm{~kW} \mathrm{~kg}^{-1}$ ) and a maximum power density of $19.7 \mathrm{~kW} \mathrm{~kg}^{-1}$ (at $43.1 \mathrm{Wh} \mathrm{kg}^{-1}$ ) (Figure $7 \mathrm{~d}$ ). The attractive energy and power densities largely result from the numerous holes of HG which greatly increase the rate capability of the battery-type anode and the specific capacity of the capacitor-type cathode (Figure 7e). 


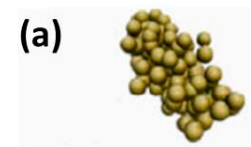

LTO cluster after ball-milling

$$
+
$$

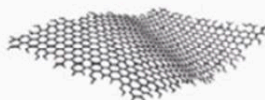

GO sheet

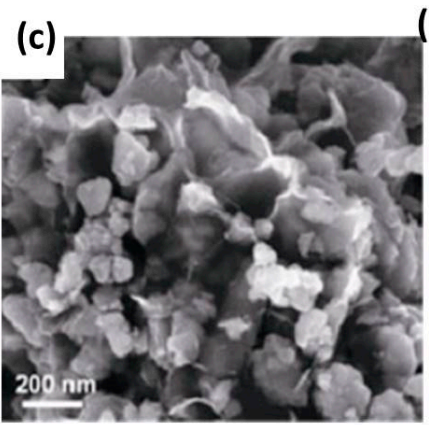
$150^{\circ} \mathrm{C}$
Ethanol/water in $\mathrm{Ar} / \mathrm{H}_{2}$

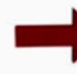

Solvothermal Heat $500^{\circ} \mathrm{C}$

(d)

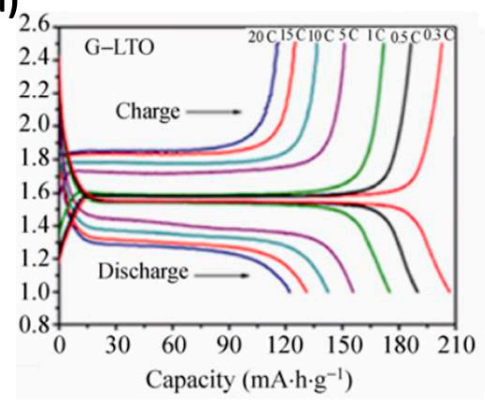

(b)

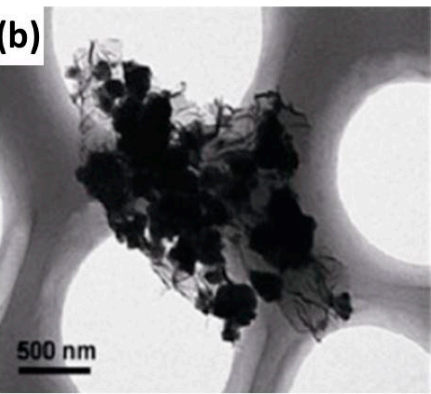

(e)

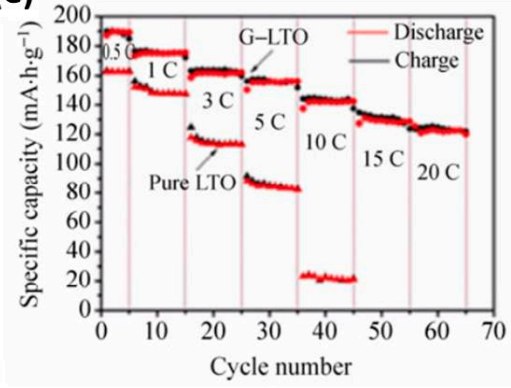

(f)
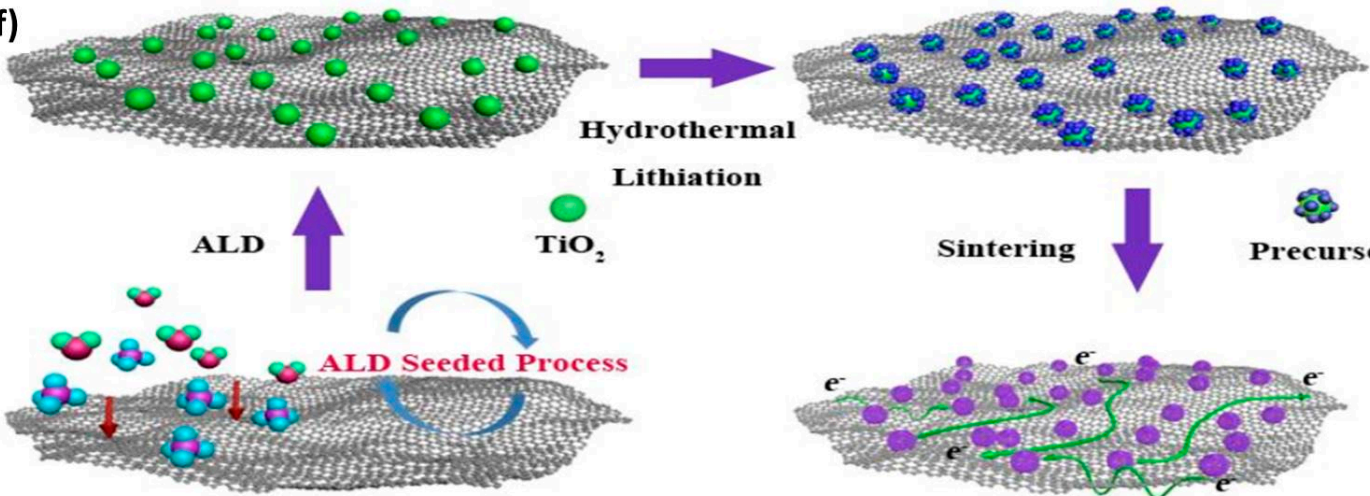

Lithiation
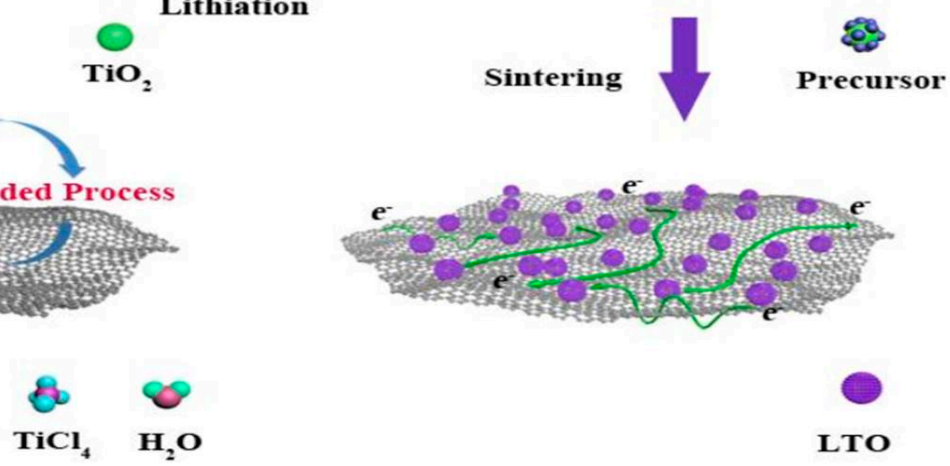

$\mathrm{TiCl}_{4} \quad \mathrm{H}_{2} \mathrm{O}$

LTO
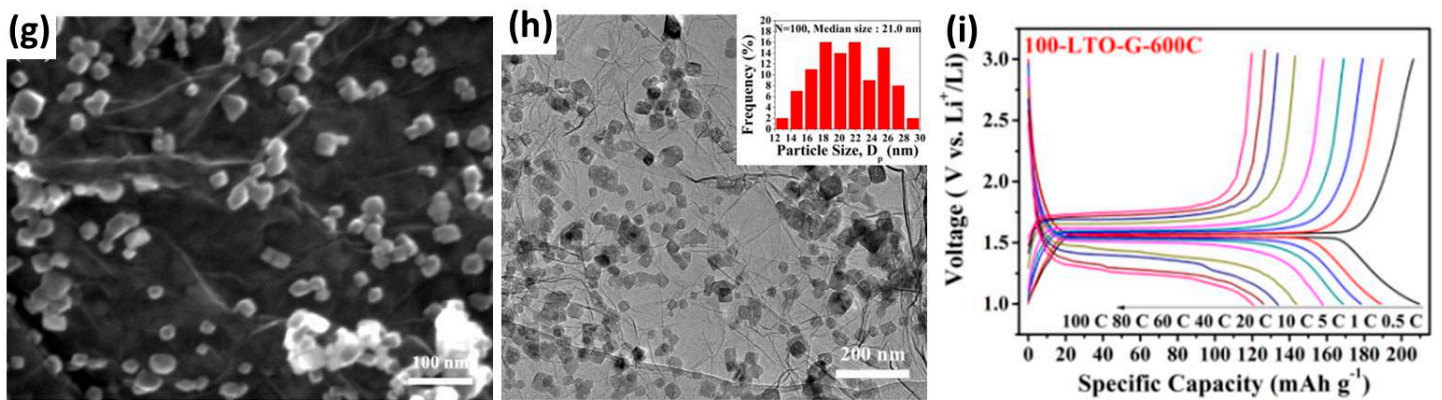

Figure 6. (a) Schematic of the synthesis of G-LTO nanocomposite; (b) SEM and (c) TEM images of G-LTO; (d) the charge/discharge profile of G-LTO; (e) the rate capabilities of G-LTO and pure LTO. Reproduced with permission from [43]. Copyright 2013, Springer. (f) Schematic illustration of a typical ALD seeded process incorporated with hydrothermal lithiation to prepare LTO/graphene composite; (g) SEM and (h) TEM images of 100-LTO-G-600C (inset: the corresponding particle diameter distribution of LTO); (i) charge/discharge potential profiles of 100-LTO-G-600C. Reproduced with permission from [77]. Copyright 2017, Elsevier. 
(a)
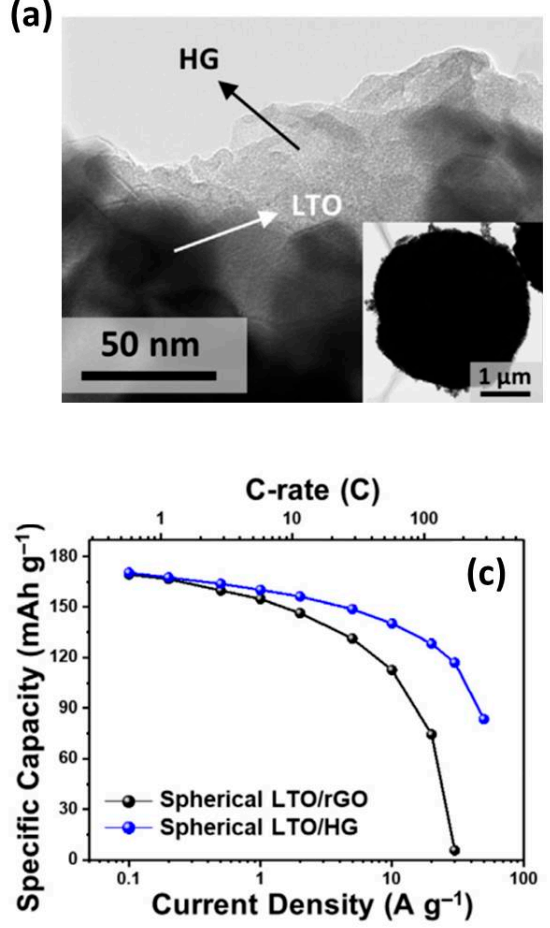

(b)
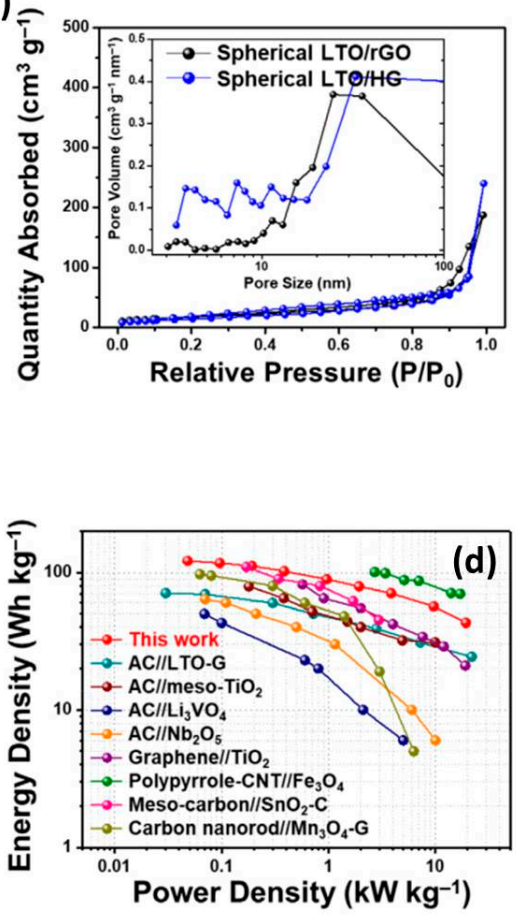

(e)

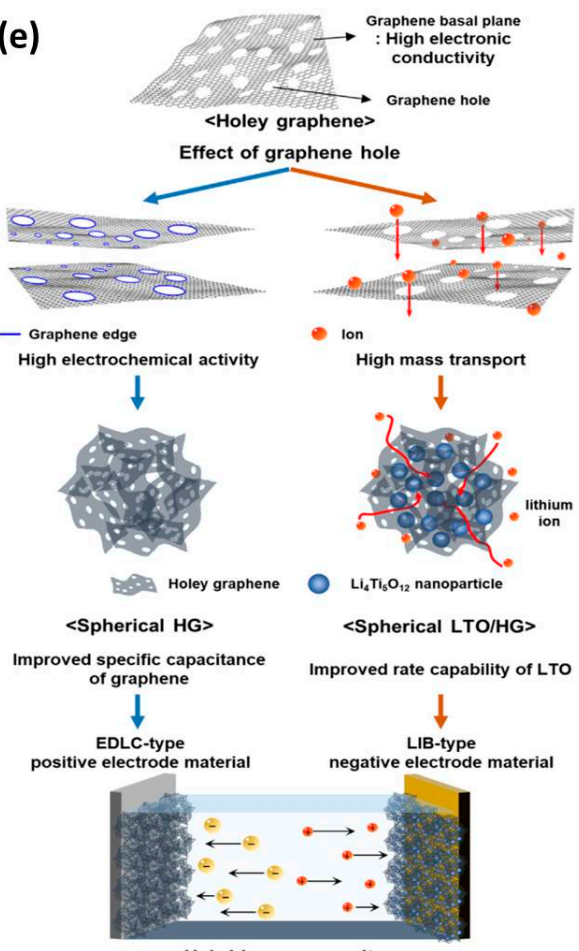

$<$ Hybrid supercapacitor>

Figure 7. (a) TEM image of spherical LTO/HG composite; (b) $\mathrm{N}_{2}$ adsorption/desorption isotherm (the inset is pore size distribution) and (c) rate capability of spherical LTO/HG and LTO/rGO composites; (d) Ragone plots for the spherical LTO/HG-based LICs and other reports; (e) schematic of LICs with HG cathode and spherical LTO/HG anode. Reproduced with permission from [78]. Copyright 2019, Elsevier.

As the above discussion, LTO has an inferior capacity (typically lower than $170 \mathrm{mAh}^{-1}$ ), which thus restrains the energy density of the obtained full cell. Accordingly, $\mathrm{TiO}_{2}$ has also been investigated as an insertion-type anode for LIBs and LICs due to its large capacity (335 mAh g ${ }^{-1}$ ), long-term cycling stability (small volume variation of $4 \%$ ) and low cost $[79,80]$. However, like $\mathrm{LTO}, \mathrm{TiO}_{2}$ also faces challenges of low electrical conductivity and slow ion diffusion coefficient $[81,82]$. To overcome these disadvantages, Wang et al. designed a 3D anatase $\mathrm{TiO}_{2}$-Graphene composite with large SSA via freeze drying [83]. The graphene wrapped $\mathrm{TiO}_{2}$ primary nanoparticles (less than $10 \mathrm{~nm}$ ) formed spherical secondary particles which further agglomerated into micrometer-sized platelet-like particles. Benefiting from the hierarchical structure and the introduction of graphene, the as-prepared $\mathrm{TiO}_{2}$-graphene delivered a high capacity of $312 \mathrm{mAh} \mathrm{g}^{-1}$ at $0.1 \mathrm{C}$ and remained $158 \mathrm{mAh} \mathrm{g}^{-1}$ at $10 \mathrm{C}$. Furthermore, LICs pairing it with AC showed an outstanding rate performance and stable cycling stability with capacitance retention of $95 \%$ after 5000 cycles. It is believed that the well-designed 3D architecture of $\mathrm{TiO}_{2}$-Graphene with ultra-small primary particle size, a homogeneous graphene coating and an adequate contact area with the liquid electrolyte account for the superior electrochemical results.

Other methods are applied to further improve the capacity and rate of graphenemodified $\mathrm{TiO}_{2}$, such as forming composite with other metal or introducing defects. For instance, Auxilia et al. fabricated a hierarchical ternary composite comprised of ${\mathrm{Au} @ \mathrm{TiO}_{2}}_{2}$ core-shell nanoparticles anchored onto rGO nanosheets $\left(\mathrm{Au} @ \mathrm{TiO}_{2} / \mathrm{RGO}\right)$ through a onepot hydrothermal method [84]. The composite yielded a large reversible capacity of $905 \mathrm{mAh} \mathrm{g}^{-1}$ at $0.1 \mathrm{~A} \mathrm{~g}^{-1}$, which was provided by the porous nanostructured RGO and $\mathrm{TiO}_{2}$ and also through alloying/de-alloying between $\mathrm{Au}$ and $\mathrm{Li}$. The $\mathrm{Au} @ \mathrm{TiO}_{2} / \mathrm{RGO}$ displayed excellent rate performance due to the high conductivity of RGO and $\mathrm{Au}$ as well as the high ion transfer coefficient. As expected, the full cell by pairing the $\mathrm{Au} @ \mathrm{TiO}_{2} / \mathrm{RGO}$ anode with AC cathode achieved an energy density of $110 \mathrm{Wh} \mathrm{kg}^{-1}$ and a power den- 
sity of $11 \mathrm{~kW} \mathrm{~kg}^{-1}$. Besides, defect engineering is another useful strategy to increase the conductivity of $\mathrm{TiO}_{2}$. The work by $\mathrm{Zhu}$ et al. demonstrated a 3D interconnected black- $\mathrm{TiO}_{2-x} /$ graphene $\left(\mathrm{B}-\mathrm{TiO}_{2-x} / \mathrm{G}\right)$ aerogel with rich oxygen vacancy [85]. The oxygendeficient porous $\mathrm{B}_{-} \mathrm{TiO}_{2-x}$ nanosheets exhibited significantly enhanced electrical conductivity and $\mathrm{Li}^{+}$diffusion kinetics and graphene can reduce the energy barrier of $\mathrm{Li}$ diffusion.

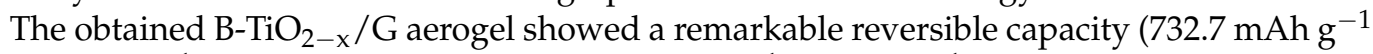
at $\left.0.1 \mathrm{~A} \mathrm{~g}^{-1}\right)$, high-rate capability (193.9 $\mathrm{mAh} \mathrm{g}^{-1}$ at $10 \mathrm{~A} \mathrm{~g}^{-1}$ ) and long-term durability, rendering it an excellent anode material for LICs. By coupling it with biomass-derived microporous carbon cathode, the as-fabricated LICs exhibited a wide operating voltage $(1.0-4.0 \mathrm{~V})$, high energy density $\left(166.4 \mathrm{Wh} \mathrm{kg}^{-1}\right)$, high power output $\left(7.9 \mathrm{~kW} \mathrm{~kg}^{-1}\right)$ as well as long cycling life ( $\sim 87 \%$ capacity retention after 3000 cycles), verifying the synergistic effects of oxygen deficiency and conductive graphene matrix.

\subsubsection{Graphene/Nb-Based Materials}

$\mathrm{Nb}$-based materials, typical intercalation-type compounds with high specific capacity, exceptional rate capability and cycling stability, are emerging as excellent anodes for LICs. Recent reports demonstrated that transition metal-based compounds with novel nanostructure displayed intercalation pseudocapacitive characteristics, making them promising anode materials to bridge the kinetics gap with the capacitor-type cathodes [86-88]. Among these materials, orthorhombic $\mathrm{Nb}_{2} \mathrm{O}_{5}$ has even more attractive rate and cycling performances due to the features of unique pseudocapacitive intercalation mechanism and rapid $\mathrm{Li}^{+}$transport throughout a-b plane without any phase transformation [89]. The pioneering works of Dunn et al. verified that $\mathrm{Nb}_{2} \mathrm{O}_{5}$ could provide $2 \mathrm{D} \mathrm{Li}^{+}$transport pathways with almost no kinetics limitations from solid-state diffusion and the $\mathrm{Li}^{+}$intercalation behavior is highly capacitive and reversible $[90,91]$ and other work showed that the intercalation induced pseudocapacitance and rate ability of $\mathrm{T}-\mathrm{Nb}_{2} \mathrm{O}_{5}$ strongly depend on the SSA and particle size [92].

To increase the electrical conductivity and further enhance the $\mathrm{Li}^{+}$diffusion rate of $\mathrm{Nb}_{2} \mathrm{O}_{5}$, carbon coating, nanostructure engineering and porosity designing are commonly adopted. For instance, Wang et al. presented a binder-free $\mathrm{Nb}_{2} \mathrm{O}_{5} @$ graphene composite via depositing $\mathrm{Nb}_{2} \mathrm{O}_{5}$ nanoparticles on the GO sheet and then thermal annealing [93]. Compared with the bare $\mathrm{Nb}_{2} \mathrm{O}_{5}$, the as-synthesized $\mathrm{Nb}_{2} \mathrm{O}_{5} @$ graphene showed a comparable capacity at $0.1 \mathrm{~A} \mathrm{~g}^{-1}$ but it achieved much higher capacity retention $(91.2 \%$ vs. $74.4 \%$ for bare $\mathrm{Nb}_{2} \mathrm{O}_{5}$ ) at $2 \mathrm{~A} \mathrm{~g} \mathrm{~g}^{-1}$, illustrating the role of graphene. Jiao et al. fabricated $\mathrm{Nb}_{2} \mathrm{O}_{5} @ \mathrm{C} /$ reduced graphene oxide $\left(\mathrm{M}-\mathrm{Nb}_{2} \mathrm{O}_{5} @ \mathrm{C} / \mathrm{rGO}\right)$ composites through annealing GO supported $\mathrm{Nb}$-based metal organic frameworks (MOFs) [94]. After pyrolysis, the $\mathrm{Nb}$-based MOFs transformed into $\mathrm{M}-\mathrm{Nb}_{2} \mathrm{O}_{5} @ \mathrm{C}$ nanoparticles with a size of $10 \mathrm{~nm}$ and homogeneously dispersed on the surface of graphene, forming a composite with interconnected porous structure. Benefiting from these characteristics, $\mathrm{M}-\mathrm{Nb}_{2} \mathrm{O}_{5} @ \mathrm{C} / \mathrm{rGO}$ showed an acceptable reversible capacity of $192 \mathrm{mAh} \mathrm{g}^{-1}$ at $0.05 \mathrm{~A} \mathrm{~g}^{-1}$ and remained $97 \mathrm{mAh} \mathrm{g}^{-1}$ at $5 \mathrm{~A} \mathrm{~g}^{-1}$. By assembled with the AC cathode, the full LICs cell delivered competitive energy and power densities of $71.5 \mathrm{Wh} \mathrm{kg}^{-1}$ and $3.9 \mathrm{~kW} \mathrm{~kg}^{-1}$, respectively. More appealingly, an excellent cycling stability of $94 \%$ retention after 2500 cycles was achieved. In these composites, the outstanding electrochemical performances of LICs are mainly attributed to the combination of merits of high conductive graphene and the nanostructured active materials with rapid surface pseudocapacitive, which is regarded to match the kinetics of the cathode.

Recently, Ti/Nb-mixed-metal oxides, especially $\mathrm{TiNb}_{2} \mathrm{O}_{7}$ (TNO), are considered to be a promising high-capacity and high-rate anode for LICs. Similar to Ti- and Nb-based compounds, the high $\mathrm{Li}^{+}$storage potential of TNO endows it with high Coulombic efficiency and excellent safety by avoiding the formation of SEI and lithium dendrite [95]. The superior theoretical capacity of TNO $\left(388 \mathrm{mAh} \mathrm{g}^{-1}\right)$ arises from the multiple Ti- and $\mathrm{Nb}$-related redox couples [96]. More importantly, TNO exhibits a more open crystal structure as $\mathrm{Ti}^{4+}$ and $\mathrm{Nb}^{5+}$ ions randomly occupy the octahedral sites, leading to a high $\mathrm{Li}^{+}$ 
diffusion coefficient [97]. For example, a holey graphene supported TNO (TNO/HG) composite was prepared by Jiao et al. through in situ anchoring nanostructured TNO onto the HG [98]. As displayed in Figure 8a, the TNO/HG had a reversible capacity of $286.2 \mathrm{mAh} \mathrm{g}^{-1}$ at $0.05 \mathrm{~A} \mathrm{~g}^{-1}$ and, impressively, a capacity retention of $73.5 \%$ was retained at $5 \mathrm{~A} \mathrm{~g}^{-1}$. Moreover, the electrochemical reactions in the TNO/HG electrode presented a typical surface-controlled capacitive behavior. The capacity contribution of surface capacitive process gradually improved as the scan rate increased with a value of $86.7 \%$ at $1 \mathrm{mV} \mathrm{s}^{-1}$ (Figure 8b). The surface-controlled Faradaic reaction is quite helpful for fast charge storage and in turn for high power output and stable long-term cycling. In accordance with the expectation, the prepared TNO/HG/ / AC LICs exhibited a long and stable life with the capacitance retention of $90.2 \%$ after 3000 cycles (Figure 8c). The full cell achieved a high energy density of $86.3 \mathrm{Wh} \mathrm{kg}^{-1}$ at a power density of $237.7 \mathrm{~W} \mathrm{~kg}^{-1}$ and still kept $28.7 \mathrm{Wh} \mathrm{kg}^{-1}$ at $3.88 \mathrm{~kW} \mathrm{~kg}^{-1}$ (Figure $8 \mathrm{~d}$ ). Besides, other reports showed that the electrochemical performance of $\mathrm{HG} / \mathrm{TNO}$ composites could be further improved by preparing TNO with rich porosity or regulating the composition of electrolytes $[99,100]$.
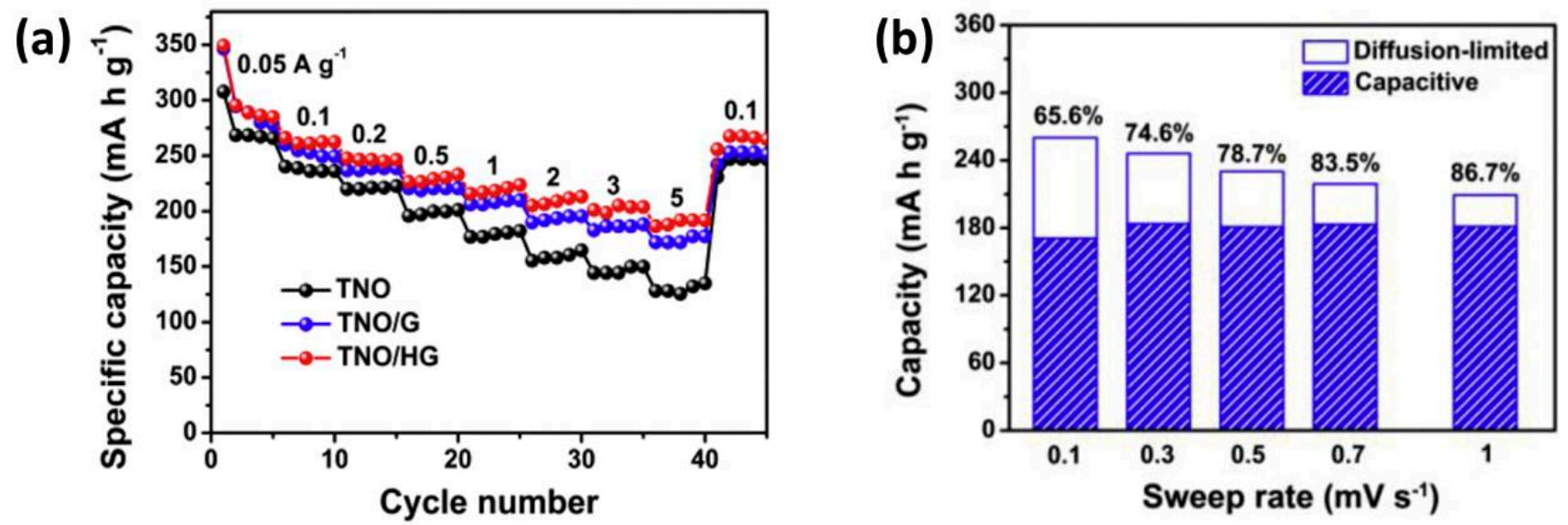

(c)
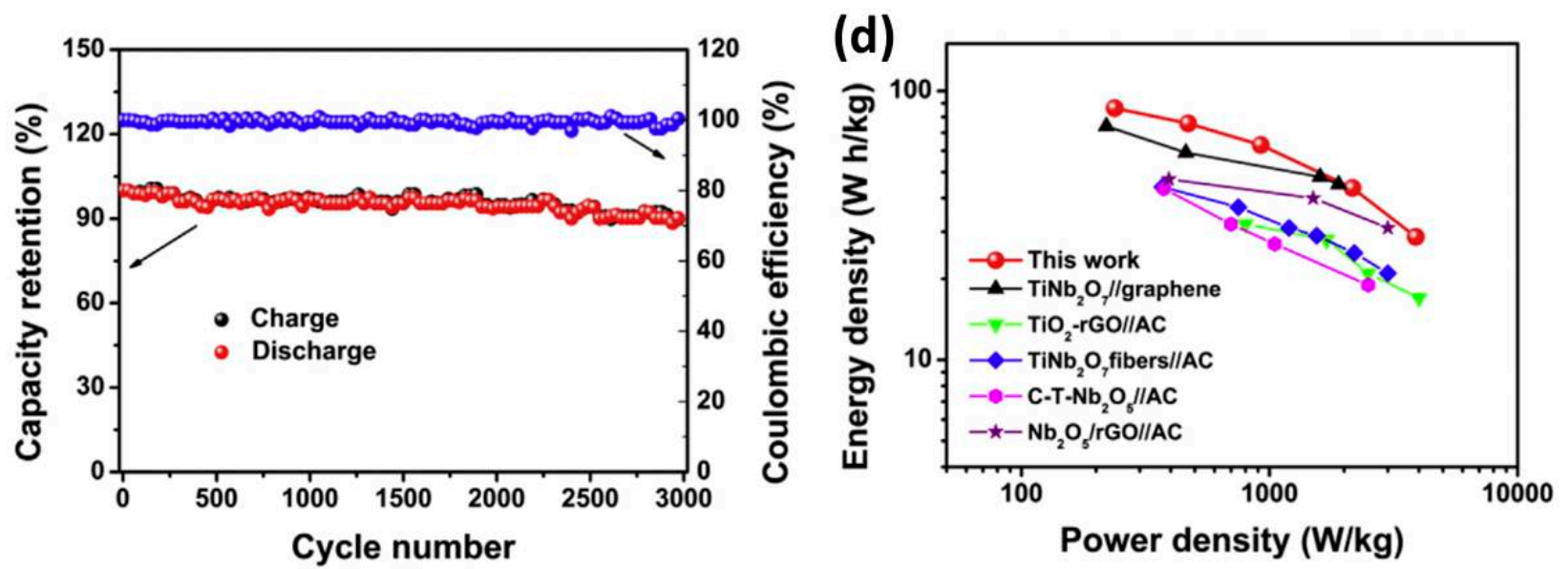

Figure 8. (a) Rate capability of TNO, TNO/G and TNO/HG; (b) capacity contributions of the capacitive and diffusionlimited at various sweep rates; (c) cycling performance of TNO/HG//AC; (d) Ragone plots of TNO/HG//AC compared with other Ti- and Nb-based LICs. Reproduced with permission from [98]. Copyright 2018, Elsevier.

Overall, $\mathrm{Ti} / \mathrm{Nb}$-based anode materials with an intercalation-type energy storage mechanism have the advantages of high working potential, stable structure and relatively better kinetics, especially when using graphene to improve the conductivity. LICs using them as anodes show outstanding electrochemical performances, as displayed in Table 2. On the other hand, unfortunately, the high $\mathrm{Li}^{+}$insertion/de-insertion potential coupled with low capacity of these materials also results in low energy density for the full-cell devices. 
Doping with heteroatoms is one possible strategy to regulate the potential and increase the capacity, which thus should be given more attention.

Table 2. Graphene/intercalation-type anode materials and their LICs performance.

\begin{tabular}{|c|c|c|c|c|c|c|c|}
\hline $\begin{array}{c}\text { Anode } \\
\text { Materials }\end{array}$ & $\begin{array}{c}\text { Capacity of } \\
\text { Anode }\left(\mathrm{mAh} \mathrm{g}^{-1}\right)\end{array}$ & $\begin{array}{l}\text { Area Loading } \\
\text { Mass }\left(\mathrm{mg} \mathrm{cm}^{-2}\right)\end{array}$ & $\begin{array}{l}\text { Cell Voltage } \\
\text { (V) }\end{array}$ & $\begin{array}{c}\text { Maximum } \\
\text { Energy Density } \\
\left(\mathrm{Wh} \mathrm{kg}^{-1}\right)\end{array}$ & $\begin{array}{c}\text { Maximum } \\
\text { Power Density } \\
\left(\mathrm{kW} \mathrm{kg}^{-1}\right)\end{array}$ & Cycling Stability & Reference \\
\hline $\mathrm{LTO}+\mathrm{G}$ & $\sim 170$ & $1.5-2.5$ & $1.5-3$ & 63 & 2.7 & $97 \%$ after 3000 & [76] \\
\hline G-LTO & 207 & / & $0-3$ & 95 & 3 & $87 \%$ after 500 & [43] \\
\hline LTO/HG & 160.2 & I & $1.5-3$ & 117.3 & 19.7 & $81.7 \%$ after 2000 & [78] \\
\hline LTO-G-600C & 350.1 & $1.5-2.8$ & $1.5-3$ & 52 & 57.6 & $97 \%$ after 2000 & [77] \\
\hline $\begin{array}{c}\mathrm{TiO}_{2} @ \mathrm{PCNF}- \\
\text { GA }\end{array}$ & 250.1 & $\sim 1.3$ & $0-3$ & 79.7 & 15 & $93.3 \%$ after 10,000 & [27] \\
\hline $\mathrm{TiO}_{2}$-FD & 312 & $\sim 1$ & $1-3$ & & & $95 \%$ after 5000 & \\
\hline Au@TiO2/RGO & 905 & $\sim 1$ & $1-4$ & 110 & 11 & $83 \%$ after 1000 & [84] \\
\hline $\mathrm{TiO}_{2}(\mathrm{~B}) @ \mathrm{C} / \mathrm{rGO}$ & 231.7 & / & $0-3$ & 59.4 & 17.3 & $70.1 \%$ after 5000 & [101] \\
\hline $\mathrm{B}-\mathrm{TiO}_{2-x} / \mathrm{G}$ & 732.7 & 1 & $1-4$ & 166.4 & 7.9 & $87 \%$ after 3000 & [85] \\
\hline $\mathrm{ZTO} / \mathrm{rGO}$ & 560 & / & $0-4.5$ & 204 & 67.5 & $76 \%$ after 1000 & [102] \\
\hline $\begin{array}{c}T- \\
\mathrm{Nb}_{2} \mathrm{O}_{5} / \mathrm{GCN}\end{array}$ & $\sim 170$ & $\sim 1$ & $0-3.5$ & 129 & 32 & $80 \%$ after 10,000 & [89] \\
\hline HG-TNO & 323 & / & $1-3.5$ & 103.9 & 17.9 & $81.8 \%$ after 10,000 & [99] \\
\hline $\mathrm{TNO} / \mathrm{HG}$ & 286.2 & $\sim 1$ & $0.8-3.2$ & 86.3 & 3.88 & $90.2 \%$ after 3000 & [98] \\
\hline $\mathrm{TNO} / \mathrm{HrGO}$ & 324.7 & $\sim 1.5$ & $0-3$ & 66.3 & 23.2 & $79.9 \%$ after 6000 & [100] \\
\hline
\end{tabular}

\subsection{Graphene/Conversion-Type Anode Materials}

The above-described intercalation-type anode materials show high rate and stable cycling due to their structural stability and relatively rapid ion diffusion. However, their low capacity results in unsatisfactory energy density. By contrast, conversion-type materials, which are mainly transition metal oxide/sulfide/nitride, have high deliverable capacity since conversion reactions are associated with the store and release of multiple numbers of electrons and $\mathrm{Li}^{+}$, rendering them promising anode candidates for high-energy LICs. Unfortunately, they usually suffer from low electrical conductivity, sluggish ion diffusion and huge volume variation during the charge/discharge process, leading to poor cycling stability, fast capacity fading and large voltage hysteresis [103]. One feasible approach is to form composites with conductive materials (like graphene) to solve the insulating drawback and to buffer the uncontrollable volume change. Moreover, developing nanostructured materials through elaborate engineering is an effective strategy to enhance the ion diffusion rate and suppress the volume change. Therefore, incorporating nanosized conversion-type metal compounds with graphene is a promising method to achieve high-rate and high-capacity anode materials for LICs.

\subsubsection{Graphene/Metal Oxides}

Metal oxides are regarded as outstanding battery-type anodes due to their low working potential $\left(<1 \mathrm{~V} \mathrm{vs.} \mathrm{Li} / \mathrm{Li}^{+}\right)$and large theoretical specific capacity $\left(>500 \mathrm{mAh} \mathrm{g}^{-1}\right)$ based on the conversion reaction. Especially, $\mathrm{Fe}_{3} \mathrm{O}_{4}$ has received tremendous attention in LICs due to its high capacity, low cost, nontoxicity, environmental friendliness and abundant resources. For example, Zhang et al. [104] designed a dual graphene-based LIC with $\mathrm{Fe}_{3} \mathrm{O}_{4} /$ graphene $\left(\mathrm{Fe}_{3} \mathrm{O}_{4} / \mathrm{G}\right)$ nanocomposite as the anode and graphene-based 3D porous carbon material (3DGraphene) as the cathode. As presented in Figure 9a, the $\mathrm{Fe}_{3} \mathrm{O}_{4} / \mathrm{G}$ composite was prepared by a simple in-situ solvothermal reaction of $\mathrm{GO}$ and Fe precursors in combination with thermal annealing while 3DGraphene was obtained from GO and sucrose using the hydrothermal reaction followed by activation. Thanks to the introduction 
of graphene which is supposed to prevent the agglomeration of $\mathrm{Fe}_{3} \mathrm{O}_{4}$ nanoparticles and to increase the electron and ion transport of the composite, the as-prepared $\mathrm{Fe}_{3} \mathrm{O}_{4} / \mathrm{G}$ exhibited a reversible capacity of $1089 \mathrm{mAh} \mathrm{g}^{-1}$ at $0.09 \mathrm{~A} \mathrm{~g}^{-1}$ and a capacity of $708 \mathrm{mAh} \mathrm{g}^{-1}$ was retained at $2.7 \mathrm{~A} \mathrm{~g}^{-1}$, much higher than those of pristine $\mathrm{Fe}_{3} \mathrm{O}_{4}$ and graphene (Figure $9 \mathrm{~b}, \mathrm{c}$ ). $\mathrm{The}_{\mathrm{Fe}} \mathrm{O}_{4} / \mathrm{G} / / 3 \mathrm{DG}$ full cell delivered ultrahigh energy densities of 204-65 Wh kg-1 over the power densities of 55-4600 $\mathrm{W} \mathrm{kg}^{-1}$, which are much better than the symmetric supercapacitor (Figure 9d). The composite of $\mathrm{Fe}_{3} \mathrm{O}_{4}$ nanocrystallites mechanically anchored among the layers of 3D graphene $\left(\mathrm{Fe}_{3} \mathrm{O}_{4}-\mathrm{G}\right)$ was prepared by Zhang et al. via low-temperature thermal annealing method [30]. By integrating with $\mathrm{AC}$, the $\mathrm{Fe}_{3} \mathrm{O}_{4}$-G-based LICs showed a high energy density of $120 \mathrm{Wh} \mathrm{kg}^{-1}$, an outstanding power density of $45.4 \mathrm{~kW} \mathrm{~kg}^{-1}$ and an excellent capacity retention of $81.4 \%$ after 10,000 cycles. Besides, one-step solvothermal method [105] and microwave-assisted solvothermal process [106] were also adopted to prepare graphene modified $\mathrm{Fe}_{3} \mathrm{O}_{4}$ composites and high performances were achieved.

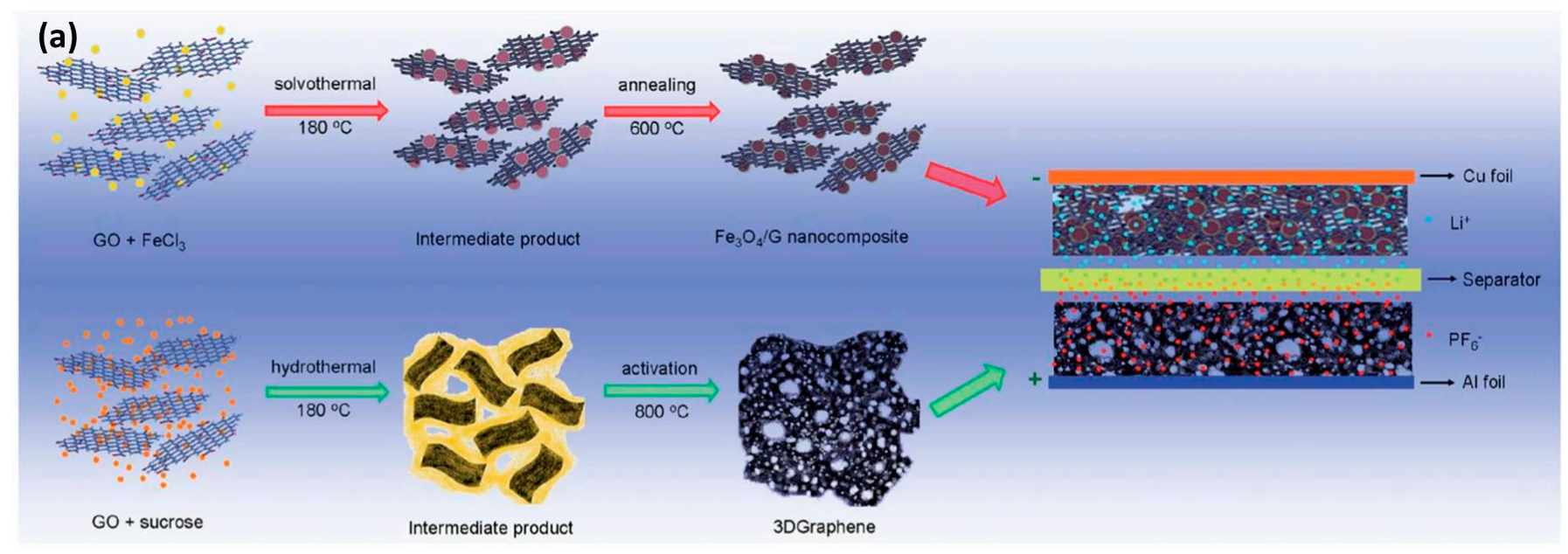

(b)

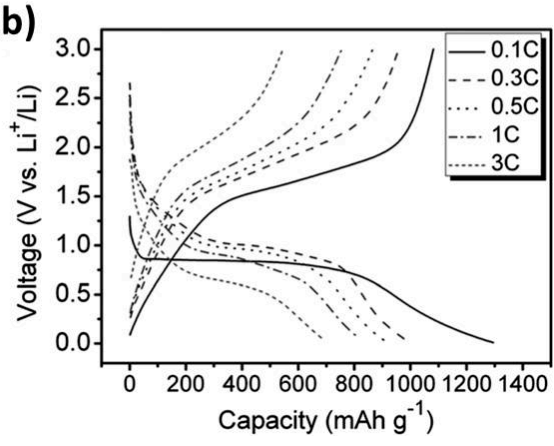

(c)

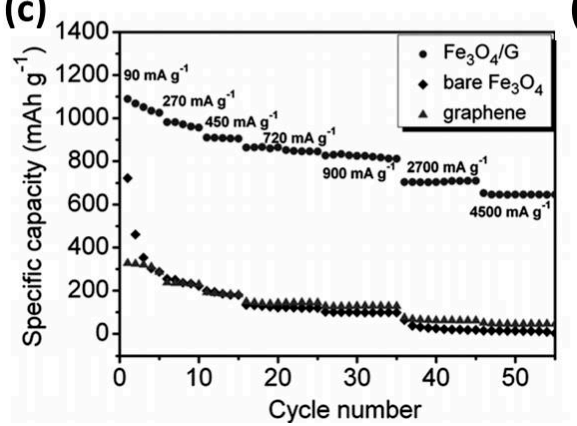

(d)

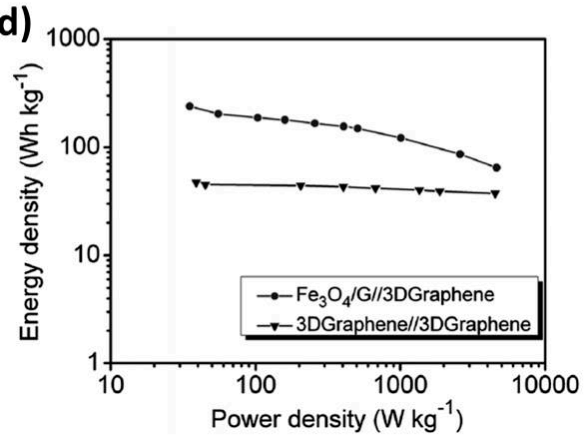

Figure 9. (a) Schematic of the synthesis of $\mathrm{Fe}_{3} \mathrm{O}_{4} / \mathrm{G}$ nanocomposite anode and 3DGraphene cathode with the configuration of the dual-graphene electrode LICs; (b) charge-discharge curves of $\mathrm{Fe}_{3} \mathrm{O}_{4} / \mathrm{G}$ electrode at different current densities; (c) rate performance of $\mathrm{Fe}_{3} \mathrm{O}_{4} / \mathrm{G}$, pristine $\mathrm{Fe}_{3} \mathrm{O}_{4}$ and graphene; (d) Ragone plots of the $\mathrm{Fe}_{3} \mathrm{O}_{4} / \mathrm{G} / / 3 \mathrm{DGraphene} \mathrm{hybrid}$ supercapacitor and 3DGraphene//3DGraphene symmetric supercapacitor. Reproduced with permission from [104]. Copyright 2013, Royal Society of Chemistry.

Graphene incorporated $\mathrm{Mn}_{3} \mathrm{O}_{4}$ and $\mathrm{MnO}$ composites have also been applied as anode materials for LICs because of their high capacity, low redox potential and abundant availability $[107,108]$. For example, Ulaganathan et al. fabricated a $\mathrm{Mn}_{3} \mathrm{O}_{4}$-graphene $\left(\mathrm{Mn}_{3} \mathrm{O}_{4}-\mathrm{G}\right)$ composite through a hydrothermal approach and used it as the anode for LIC by pairing with AC cathode [109]. With the introduction of graphene to improve the conductivity and prevent the agglomeration of $\mathrm{Mn}_{3} \mathrm{O}_{4}$ nanoparticles, the obtained LICs displayed high energy and power densities of $142 \mathrm{Wh} \mathrm{kg}^{-1}$ and of $6.5 \mathrm{~kW} \mathrm{~kg}^{-1}$, respectively, as well as a stable cycling with capacity retention of $\sim 80 \%$ after 9000 cycles. Another work by Zhou's group presented a MnO-graphene composite (MnO@GNS) prepared by uni- 
formly dispersing $\mathrm{MnO}$ nanocrystals on the surface of graphene [110]. The well-designed $3 \mathrm{D}$ composite exposes a large portion of the exterior interface of the active phase and thus showed a high capacity of over $1000 \mathrm{mAh} \mathrm{g}^{-1}$ and an exceptional rate capability of $436 \mathrm{mAh} \mathrm{g}^{-1}$ at $5 \mathrm{~A} \mathrm{~g}^{-1}$. The novel framework of nanosized $\mathrm{MnO}$ anchored on flexible graphene formed a robust structure and brings about rapid electron and ion transport, which thus enables the composite with high energy density, outstanding power output and long-term cycling stability. More recently, Yang et al. reported a 1D graphene nanoscroll wrapped $\mathrm{MnO}$ nanoparticle (GNS@MnO) material through a simple freeze-drying process followed by thermal treatment (Figure 10a) [44]. As shown in the TEM image of the optimal GNS@MnO-600 (Figure 10b), MnO nanoparticles were completely and uniformly wrapped in the GNS to form a nanotube-like structure so that the drawbacks associated with insulating, agglomeration and volume variation of $\mathrm{MnO}$ could be perfectively solved. As a result, GNS@MnO-600 showed a high capacity of $766 \mathrm{mAh} \mathrm{g}^{-1}$ at $0.1 \mathrm{~A} \mathrm{~g}^{-1}$ and also a remarkable rate performance ( $437 \mathrm{mAh} \mathrm{g}^{-1}$ at $\left.5 \mathrm{~A} \mathrm{~g}^{-1}\right)$. Furthermore, the kinetics behavior of GNS@MnO-600 displayed that surface capacitive contribution dominated the overall $\mathrm{Li}^{+}$storage (Figure 10c), ensuring an enhanced ion diffusion coefficient. As expected, LIC constructed with GNS@MnO-600 anode and 3D framework AC delivered a maximum energy and power densities of $197 \mathrm{Wh} \mathrm{kg}^{-1}$ and $23.5 \mathrm{~kW} \mathrm{~kg}^{-1}$ and a long cycling life (84.8\% capacity remained after 3000 cycles).
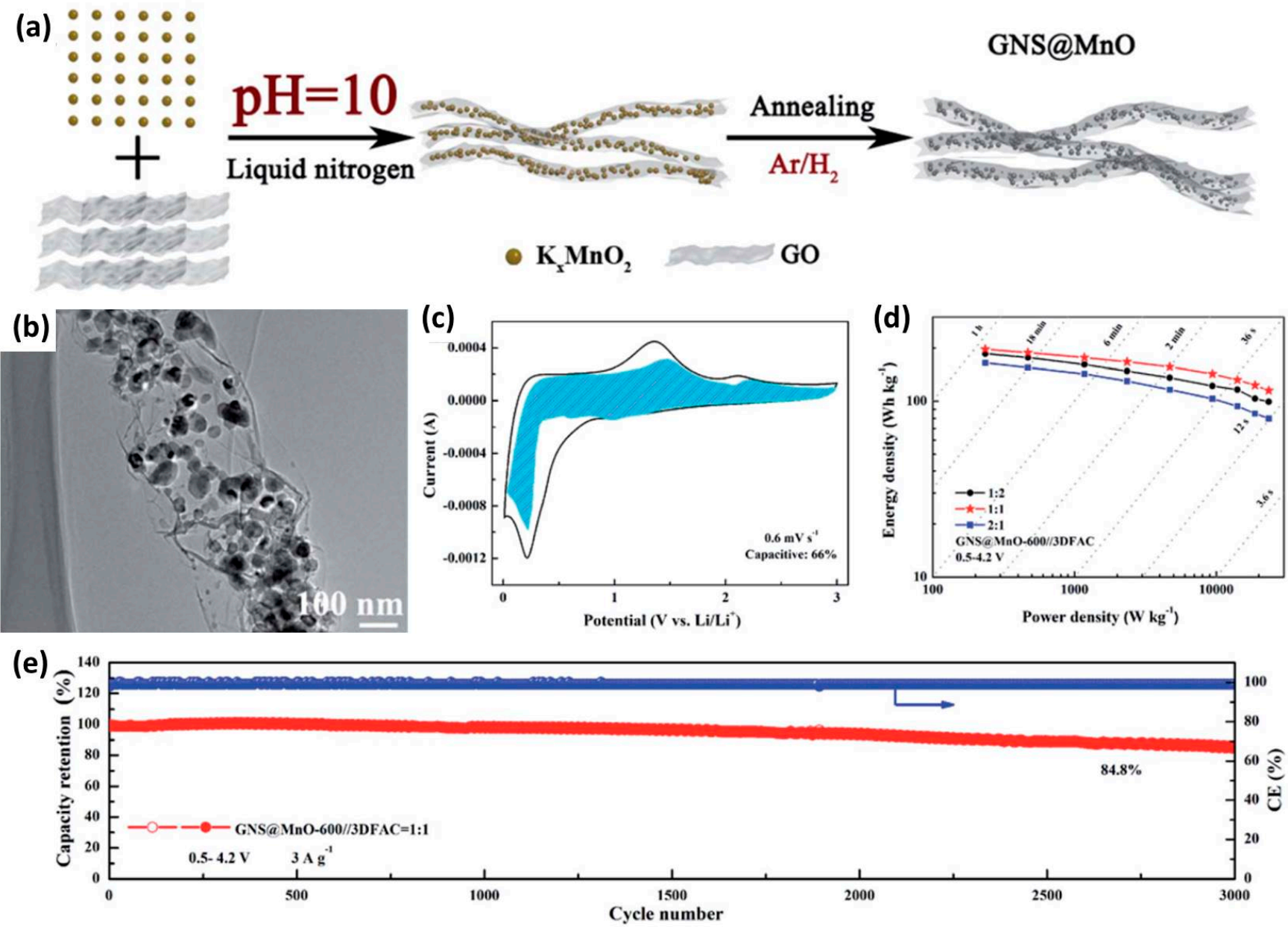

Figure 10. (a) Schematic illustration of the preparation of GNS@MnO composites; (b) TEM image of GNS@MnO-600; (c) CV curve of GNS@MnO-600 at $0.6 \mathrm{mV} \mathrm{s}^{-1}$ and the corresponding capacitive contribution (shadowed area); (d) Ragone plots of GNS@MnO-600//3DFAC with different mass ratios; (e) cycling stability of the optimal LIHC device of GNS@MnO600//3DFAC. Reproduced with permission from [44]. Copyright 2021, Royal Society of Chemistry. 
Mo-based oxides have received considerable attention recently as anode materials in LICs due to their high theoretical capacity and excellent chemical stability [111]. Graphenewrapped $\mathrm{MoO}_{3}$ nanobelt foam was prepared by a hydrothermal reaction [112]. The as-fabricated composite showed a 3D interconnected porous microstructure with nanosized $\mathrm{MoO}_{3}$ uniformly wrapped by the ultrathin graphene sheets. This novel structure ensures a good electrolyte accessibility and benefits to improving electric conductivity and accommodating the stress from volume change. Moreover, theoretical calculation revealed that graphene could reduce the diffusion energy barrier of $\mathrm{Li}^{+}$adsorbed on the surface of $\mathrm{MoO}_{3}$ nanobelts while kinetics analysis showed that $72 \%$ of the capacity is contributed by capacitive mechanism, making the composite a high-rate anode. By pairing with a 3D graphene-wrapped polyaniline nanotube foam derived carbon, the full cell exhibited high energy and power densities of $128.3 \mathrm{Wh} \mathrm{kg}^{-1}$ and $13.5 \mathrm{~kW} \mathrm{~kg}^{-1}$, respectively. In addition, a long-term cycling durability was achieved with the capacity retention of $90 \%$ after 3000 cycles. Compared with $\mathrm{MoO}_{3}, \mathrm{MoO}_{2}$ has much improved electrical conductivity, but it still suffers from poor bulk lithium-ion diffusivity and large volume change. Therefore, by annealing GO coated $\mathrm{Mo} / \mathrm{Cu}-\mathrm{MOF}$ in combination with etching metallic $\mathrm{Cu}$ particles, Ock et al. prepared a high-capacity and high-rate graphene modified $\mathrm{MoO}_{2}$ anode $\left(\mathrm{MoO}_{2} @ \mathrm{rGO}\right)$ [113]. The composite is composed of MOFs-derived ultrafine $\mathrm{MoO}_{2}$ particles embedded in mesoporous carbon framework and further coated with rGO shell. Owing to the synergistic effects of mesoporous channels for rapid $\mathrm{Li}^{+}$diffusion, carbon-rGO pathways for facile electron transport and nanosized $\mathrm{MoO}_{2}$ for high capacity, the as-fabricated $\mathrm{MoO}_{2} @ \mathrm{rGO}$ delivered an extremely high capacity of $1474.9 \mathrm{mAh} \mathrm{g}^{-1}$ at $0.1 \mathrm{~A} \mathrm{~g}^{-1}$ and still maintained $551 \mathrm{mAh} \mathrm{g}^{-1}$ at an ultrahigh current density of $20 \mathrm{~A} \mathrm{~g}^{-1}$. As a result, the full cell constructed with $\mathrm{MoO}_{2} @ \mathrm{rGO}$ as anode and polyaniline chain-integrated rGO as cathode exhibited a remarkable energy density of $242 \mathrm{Wh} \mathrm{kg}^{-1}$, ultrafast power density of $28.75 \mathrm{~kW} \mathrm{~kg}^{-1}$ and long-term stability with capacity retention of $96 \%$ after 10,000 cycles.

\subsubsection{Graphene/Metal Sulfides or Nitrides}

$\mathrm{MoS}_{2}$, a typical 2D layered transition metal dichalcogenides, has drawn growing research interest because of its tunable morphology, structure and surface chemistry, making it an appealing electrode material in LIBs, supercapacitors and hybrid devices [114,115]. Notably, $\mathrm{MoS}_{2}$ has a larger interlayer distance of $0.62 \mathrm{~nm}$ via weak van der Waals stacking along the c-axis, which is regarded to facilitate the $\mathrm{Li}^{+}$insertion and transport [116]. The capacity of $\mathrm{MoS}_{2}$ could be regulated by the depth of discharge according to lithium storage mechanism [117]. For example, $\mathrm{MoS}_{2}$ only accommodates a theoretical capacity of around $167 \mathrm{mAh} \mathrm{g}^{-1}$ without destroying the 2D layered structure at a charge/discharge voltage between $1.0 \mathrm{~V}$ and $3.0 \mathrm{~V}$ (vs. $\mathrm{Li} / \mathrm{Li}^{+}$) through an intercalation/de-intercalation process. On the other hand, it could deliver a capacity of up to $669 \mathrm{mAh} \mathrm{g}^{-1}$ based on a four-electron transfer reaction followed by a conversion-type mechanism. Under this condition, unfortunately, the structure is severely destroyed, and a large volume variation occurs. Moreover, $\mathrm{MoS}_{2}$ also faces challenges of poor electrical conductivity and easy restacking. To tackle these issues, introducing graphene to form composites is a feasible strategy to develop advanced $\mathrm{MoS}_{2}$-based anode materials [118]. Zhang et al. designed a 3D porous composite with $\mathrm{MoS}_{2}$ flocculent nanostructure uniformly incorporated onto 3D graphene $\left(\mathrm{MoS}_{2} @ 3 \mathrm{DG}\right)$ by a solution method (Figure 11a) [119]. Thanks to the highly conductive graphene and the interconnected porous structure (Figure 11b), the $\mathrm{MoS}_{2} @ 3 \mathrm{DG}$ had significantly enhanced rate capability with capacity of 1024 and $688 \mathrm{mAh} \mathrm{g}^{-1}$ at 0.1 and $8 \mathrm{~A} \mathrm{~g}^{-1}$, respectively, which is much better than that of pristine $\mathrm{MoS}_{2}$ (Figure 11c). The fabricated LIC with $\mathrm{MoS}_{2} @ 3 \mathrm{DG}$ as the anode and nitrogen-doped porous carbon as the cathode exhibited a maximum energy density of $156 \mathrm{Wh} \mathrm{kg}^{-1}$ at $197 \mathrm{~W} \mathrm{~kg}^{-1}$ and remained $97 \mathrm{Wh} \mathrm{kg}^{-1}$ at a high-power density of $8.3 \mathrm{~kW} \mathrm{~kg}^{-1}$. The full cell also demonstrated an acceptable cycling performance with a capacity retention of $78 \%$ after 2000 cycles while the pristine $\mathrm{MoS}_{2}$-based LIC only cycled for less than 100 times, illustrating the critical role of graphene. 


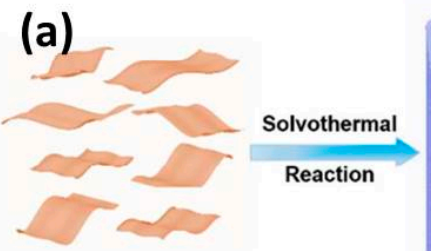

GO sheets

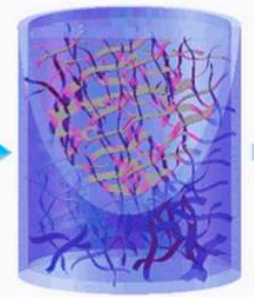

3DG alcogel

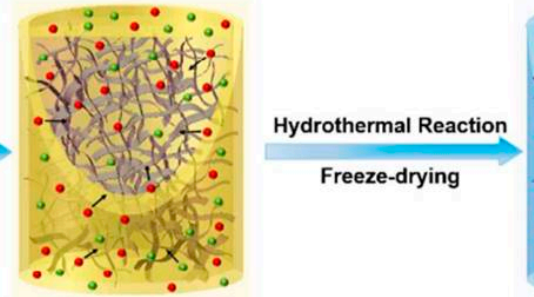

3DG hydrogel

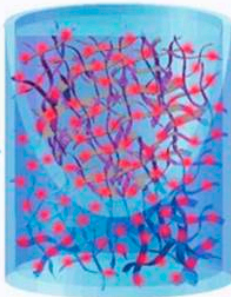

$\mathrm{MoS}_{2} @ 3 \mathrm{DG}$ aeroge
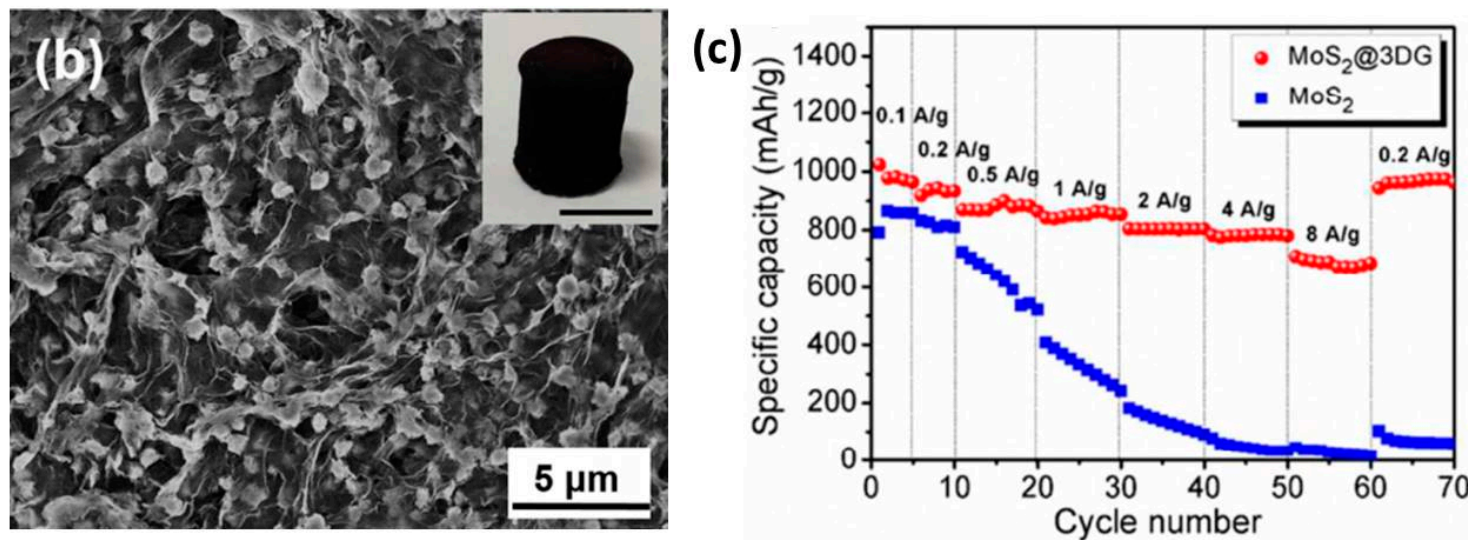

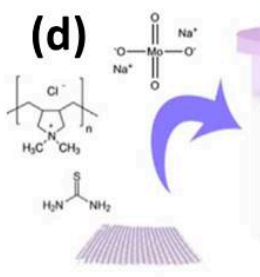

Mo atom

- S atom

- C atom

Graphene

1. $\mathrm{MoS}_{2}$ nanoflower

$\approx$ PDDA
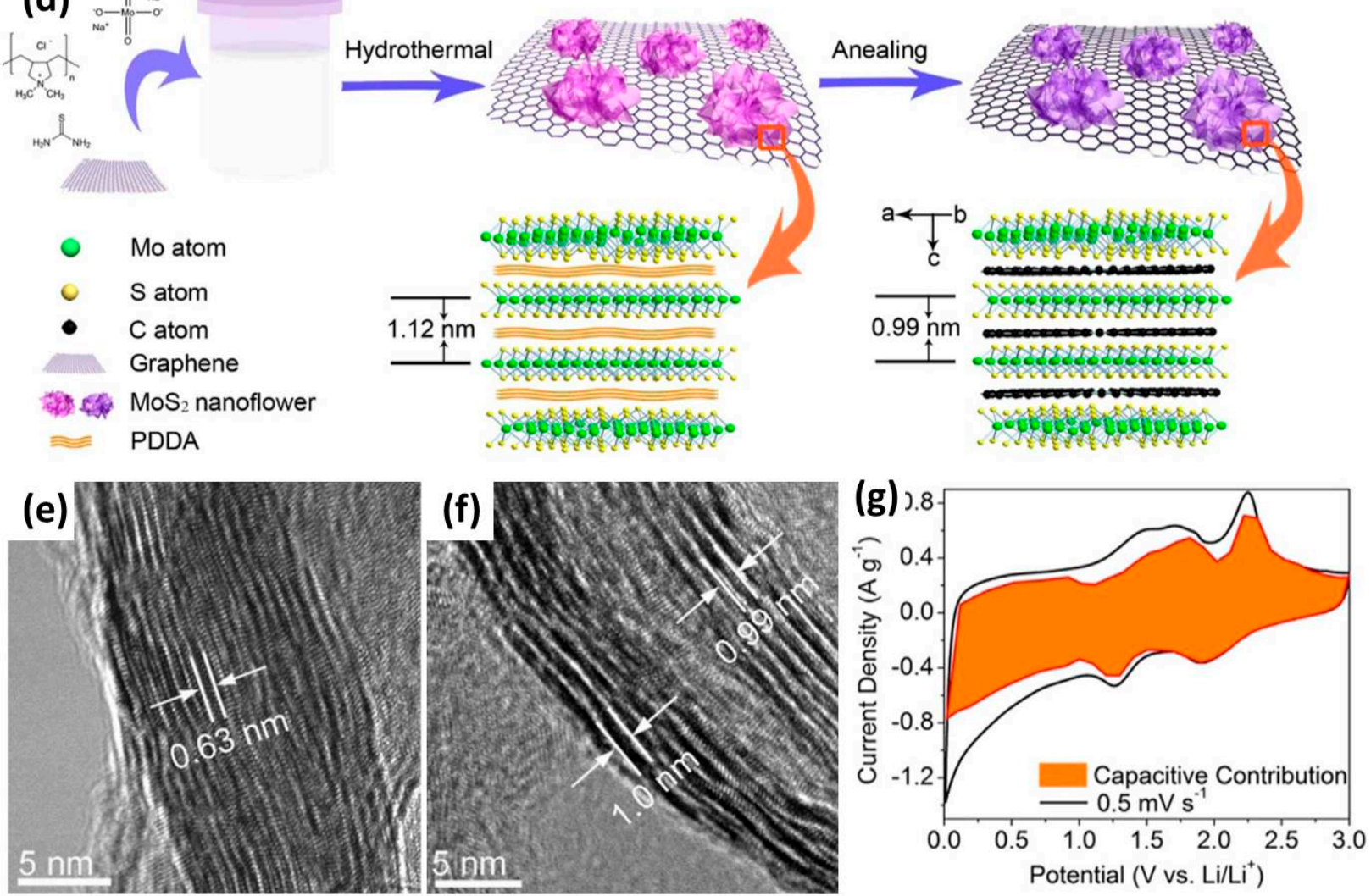

Figure 11. Conts 

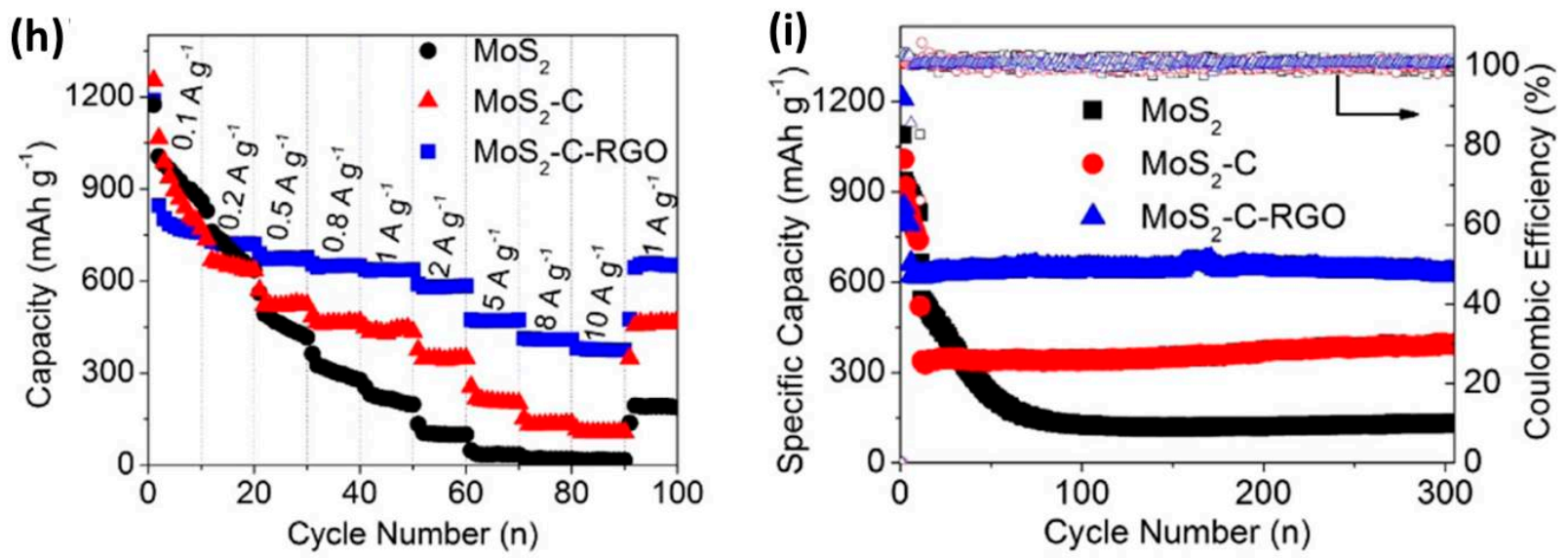

Figure 11. (a) Schematic of the fabrication of the $\mathrm{MoS}_{2} @ 3 D G$ composite; (b) SEM image of the MoS 2 @3DG (inset: optical photograph of $\mathrm{MoS}_{2} @ 3 \mathrm{DG}$ bulk sample); (c) rate capability of $\mathrm{MoS}_{2}, \mathrm{MoS}_{2} @ 3 D G$. Reproduced with permission from [119]. Copyright 2016, American Chemical Society. (d) Schematic of the synthesis of $\mathrm{MoS}_{2}-\mathrm{C}-\mathrm{RGO}$; high-resolution TEM images of (e) pure $\mathrm{MoS}_{2}$ and (f) $\mathrm{MoS}_{2}-\mathrm{C}-\mathrm{RGO}$; (g) voltametric response for $\mathrm{MoS}_{2}-\mathrm{C}-\mathrm{RGO}$ electrode at a sweep rate of $0.5 \mathrm{mV} \mathrm{s}^{-1}$ (the capacitive contribution to the total current is shown by the orange region); (h) rate capability and (i) cycle stability of pure $\mathrm{MoS}_{2}, \mathrm{MoS}_{2}-\mathrm{C}$ and $\mathrm{MoS}_{2}-\mathrm{C}-\mathrm{RGO}$ electrodes. Reproduced with permission from [120]. Copyright 2017, Elsevier.

The layer space of $\mathrm{MoS}_{2}$ could be elaborately engineered to increase the ion diffusion rate so that the power output could be improved. Wang et al. synthesized $\mathrm{MoS}_{2}$-carbon microflowers supported on reduced graphene oxide $\left(\mathrm{MoS}_{2}-\mathrm{C}-\mathrm{RGO}\right)$ via a hydrothermal reaction and annealing (Figure 11d) [120]. The spacer could be inserted into $\mathrm{MoS}_{2}$ layers during the hydrothermal process and transformed to carbon layer after thermal treatment. As demonstrated in Figure 11e and f, the inter-layer space between adjacent $\mathrm{MoS}_{2}$ monolayers for $\mathrm{MoS}_{2}$-C-RGO is $\sim 1 \mathrm{~nm}$ compared with the value of $0.63 \mathrm{~nm}$ for the conventional $\mathrm{MoS}_{2}$ nanosheets. The conductivity of the interlayer modified $\mathrm{MoS}_{2}$ was further enhanced through incorporating RGO. As a result, the obtained composite showed a capacitive behavior-controlled lithium storage (79.3\%) (Figure 11g). Benefiting from these characteristics, $\mathrm{MoS}_{2}-\mathrm{C}-\mathrm{RGO}$ exhibited better rate and cycling performance than pure $\mathrm{MoS}_{2}$ and $\mathrm{MoS}_{2}-\mathrm{C}$ (Figure 11h,i). By integrating with polyaniline derived porous carbon cathode, the obtained device presented a high energy density of $188 \mathrm{Wh} \mathrm{kg}^{-1}$ (at $200 \mathrm{~W} \mathrm{~kg}^{-1}$ ) and kept $45.3 \mathrm{Wh} \mathrm{kg}^{-1}$ even at an extremely high-power density of $40 \mathrm{~kW} \mathrm{~kg}^{-1}$ in addition to a long-term cycling stability with a retention of $80 \%$ after 10,000 cycles.

Recent investigation of vanadium nitride (VN) has shown exciting results as a conversion-type anode for LIBs due to its high theoretical capacity, low lithiation/delithiation potential and small electrical resistivity [121]. Yan et al. [122] reported a 3D porous architecture by integrating VN nanowires with graphene (3D VN-RGO) and applied it as the anode. The 3D porous structure with interconnected diffusion channels offered a good pathway for ion transport and efficient access of the electrolyte to the electrode surface. Additionally, the overall conductivity of the composite could be further increased by the highly conductive graphene network while the porous structure of VN nanowire reduced ion diffusion distance and endowed it with capacitive charge storage behavior. Benefiting from these intriguing characteristics, the 3D VN-RGO composite showed a capacity of 640 and $270 \mathrm{mAh} \mathrm{g}^{-1}$ at 0.1 and $5 \mathrm{~A} \mathrm{~g}^{-1}$, respectively. These values are much higher than those of pure $\mathrm{VN}\left(400\right.$ and $120 \mathrm{mAh} \mathrm{g}^{-1}$ ), clearly demonstrating the importance of the 3D architecture in improving the electrochemical performance. Based on the 3D VN-RGO anode and an activated polyaniline-derived carbon cathode, the asassembled full cell delivered a maximum energy of $162 \mathrm{Wh} \mathrm{kg}^{-1}$ at $0.2 \mathrm{~kW} \mathrm{~kg}^{-1}$ and a value of $\sim 64 \mathrm{Wh} \mathrm{kg}^{-1}$ was achieved even at an ultrahigh power density of $10 \mathrm{~kW} \mathrm{~kg}^{-1}$.

From the above discussions and as also summarized in Table 3, we can conclude that graphene plays an important role in improving the electrochemical performances of LICs with high-capacity conversion-type compounds as the anode. Graphene not 
only acts as an excellent conductive additive to improve the conductivity of the composite, but also serves as the flexible matrix to suppress the growth and agglomeration of conversion-type nanoparticles as well as accommodating the large volume change during the charge/discharge process. These characteristics endow conversion-type anode-based LICs with enhanced energy and power densities and long-term cycling stability by narrowing the kinetics gap between the battery-type and capacitor-type electrodes, increasing ion diffusion rate and inhibiting structural degradation. Even so, there is still a long way to go for conversion-type materials to meet the ever-growing requirements of commercial devices, especially in terms of power output and cycling life. Developing nanosized metal compounds with pseudocapacitive behavior might be a promising research direction to further improve the electrochemical properties.

Table 3. Graphene/conversion-type anode materials and their LICs performance.

\begin{tabular}{|c|c|c|c|c|c|c|}
\hline Anode Materials & $\begin{array}{c}\text { Capacity of } \\
\text { Anode }\left(\mathrm{mAh} \mathrm{g} \mathrm{g}^{-1}\right)\end{array}$ & Cell Voltage (V) & $\begin{array}{c}\text { Maximum } \\
\text { Energy Density } \\
\left(\mathrm{Wh} \mathrm{kg}^{-1}\right)\end{array}$ & $\begin{array}{l}\text { Maximum Power } \\
\text { Density }\left(\mathrm{kW} \mathrm{kg}^{-1}\right)\end{array}$ & Cycling Stability & Reference \\
\hline $\mathrm{Fe}_{3} \mathrm{O}_{4} / \mathrm{G}$ & 1000 & $1-4$ & 204 & 4.6 & $70 \%$ after 1000 & [104] \\
\hline $\mathrm{Fe}_{3} \mathrm{O}_{4}-\mathrm{G}$ & 820 & $1-4$ & 120 & 45.4 & $81.4 \%$ after 10,000 & [30] \\
\hline $\mathrm{ZnFe}_{2} \mathrm{O}_{4} @ \mathrm{C} / \mathrm{RGO}$ & 1011 & $1-4.2$ & 174 & 51.4 & $80.5 \%$ after 10,000 & [123] \\
\hline CG@SF & 1445 & $1-4$ & 121 & 18 & $87 \%$ after 2000 & [124] \\
\hline $\mathrm{Mn}_{3} \mathrm{O}_{4}-\mathrm{G}$ & 643 & $1-4$ & 97.2 & 6.25 & $76.8 \%$ after 3000 & [107] \\
\hline $\mathrm{Mn}_{3} \mathrm{O}_{4}-\mathrm{G}$ & 643 & $1.5-4$ & 142 & 6.5 & $80 \%$ after 9000 & [109] \\
\hline GNS@MnO & 766 & $0.5-4.2$ & 197 & 23.5 & $84.8 \%$ after 3000 & [44] \\
\hline MnO@GNS & 1350 & $1-4$ & 127 & 25 & $76 \%$ after 3000 & [110] \\
\hline $\mathrm{MoS}_{2}-\mathrm{RGO}$ & 860 & $0-4$ & 188 & 40 & $80 \%$ after 10,000 & [120] \\
\hline $\mathrm{MoS}_{2} @ 3 \mathrm{DG}$ & 1022.3 & $0-4$ & 156 & 8.31 & $78 \%$ after 2000 & [119] \\
\hline $\mathrm{MoO}_{2} @ \mathrm{rGO}$ & 1474.9 & $1.25-4.5$ & 242 & 28.75 & $93 \%$ after 10,000 & [113] \\
\hline $3 \mathrm{DMoO}_{3} / \mathrm{GNSs}$ & $\sim 1100$ & $0-3.8$ & 128.3 & 13.5 & $90 \%$ after 3000 & [112] \\
\hline CoO-rGO & 1674 & $1-4$ & 132 & 35.8 & $84.7 \%$ after 5000 & [29] \\
\hline 3DVN-RGO & $\sim 640$ & $0-4$ & 162 & 10 & $83 \%$ after 1000 & [122] \\
\hline
\end{tabular}

\subsection{Graphene/Alloying-Type Anode Materials}

With the continuous demand of high-energy LICs, increasing attention has been focused on exploring $\mathrm{Si} / \mathrm{Sn}$-based materials with the alloying/de-alloying mechanism because of their high theoretical capacity, low lithiation potential and abundant availability $[125,126]$. Nevertheless, the slow Faradaic reaction and huge volume variation during the charge/discharge process result in unsatisfactory power density and short cycling life. In order to tackle these disadvantages, nanostructure engineering and forming composite with highly conductive materials are possible solutions to these issues $[127,128]$. With this in mind, carbon modified nanostructured $\mathrm{Si} / \mathrm{Sn}$ anodes have been developed and attractive electrochemical properties have been demonstrated [31,129-131]. Particularly, graphene, with merits of stable and flexible 2D sheets, large SSA, and high electrical conductivity, has been applied to form composites with these alloying-type materials and develop high-performance anodes for LICs [132,133]. For example, Jiang et al. constructed a 3D conductive framework of graphene aerogel supported Si nanoparticles (Si@GA) through a hydrothermal reaction of $\mathrm{GO}$ and $\mathrm{SiO}_{2}$ followed by magnesiothermic reduction (Figure 12a) [134]. As shown in Figure 12b, Si particles are almost fully encapsulated by graphene to form a 3D conductive composite with high surface area and abundant pores, which not only buffers the severe volume expansion of Si but also facilitates electron transfer and rapid electrolyte penetration and diffusion. Consequently, the optimal composite (Si@GA-2) exhibited outstanding rate capability with reversible capacity of 1327.3 and $551.9 \mathrm{mAh} \mathrm{g}^{-1}$ at 0.1 and $5 \mathrm{~A} \mathrm{~g}^{-1}$, respectively (Figure 12c,d). More importantly, the 
sample had a stable cycling over 200 cycles with capacity retention of $98.2 \%$, proving the structural stability of the composite. To match the advanced anode, the boron carbonitride nanotubes (BCNNTs) with high-rate pseudocapacitive behavior and desirable capacity was applied as cathode to assemble a $4.5 \mathrm{~V} \mathrm{LIC,} \mathrm{which} \mathrm{delivered} \mathrm{a} \mathrm{maximum} \mathrm{energy} \mathrm{and}$ power density of $197.3 \mathrm{Wh} \mathrm{kg}^{-1}$ and $11.2 \mathrm{~kW} \mathrm{~kg}^{-1}$, respectively (Figure 12e). In addition, a desirable cycling stability of $82.4 \%$ was achieved after 10,000 cycles.

Graphene modified metallic $\mathrm{Sn}$ and $\mathrm{SnO}_{2}$ composites are also emerging as advanced anode for LICs. Stacked reduced graphene oxide-tin (SrGO-Sn) composite was prepared by $\mathrm{Ahn}$ et al. [135] via co-reduction of graphene oxide and $\mathrm{Sn}^{2+}$. However, the obtained SrGO-Sn showed unsatisfactory capacity due to the restack structure of graphene and the incomplete encapsulation and uneven distribution of Sn particles, which thus results in relatively low energy density. However, the full cell device had an ultra-long cycling life of 120,000 cycles with capacity retention of $60 \%$. Ajuria et al. reported a self-standing, binderfree 3D macroporous $\mathrm{rGO}$ foam decorated with $\mathrm{SnO}_{2}$ nanoparticles $\left(\mathrm{SnO}_{2}-\mathrm{rGO}\right)$ [132] The $\mathrm{SnO}_{2}-\mathrm{rGO}$ composite had an open $3 \mathrm{D}$ porous network with nanosized $\mathrm{SnO}_{2}$ decorating on the graphene sheets, forming a highly conductive framework with facile ion diffusion pathways. As an anode, the obtained sample delivered a reversible capacity of $950 \mathrm{mAh} \mathrm{g}^{-1}$ at $0.05 \mathrm{~A} \mathrm{~g}^{-1}$, displaying a promising battery-type electrode for high-energy LICs. By integrating it with a thermally expanded and activated reduced graphene oxide (aTEGO) cathode, the a-TEGO// $\mathrm{SnO}_{2}-\mathrm{rGO}$ LICs demonstrated outstanding electrochemical results, including a maximum energy and power density of $186 \mathrm{Wh} \mathrm{kg}^{-1}$ and $10 \mathrm{~kW} \mathrm{~kg}^{-1}$, respectively, as well as long a long-term cycling (70\% capacity retention after 5000 cycles).

Benefiting from the incorporation of graphene, LICs based on alloying-type anodes demonstrate exciting electrochemical performances, as discussed above and summarized in Table 4. Similar to the role in the conversion-type materials, graphene makes a significant contribution in increasing the electrical conductivity and preventing the pulverization of alloying-type anode. However, the imbalances in term of capacity, rate and cycling stability between the alloying-type anode and the capacitor-type cathode are still unsatisfactory. Therefore, future research should pay more attention on the developing nanostructured materials with improved kinetics and structural stability.

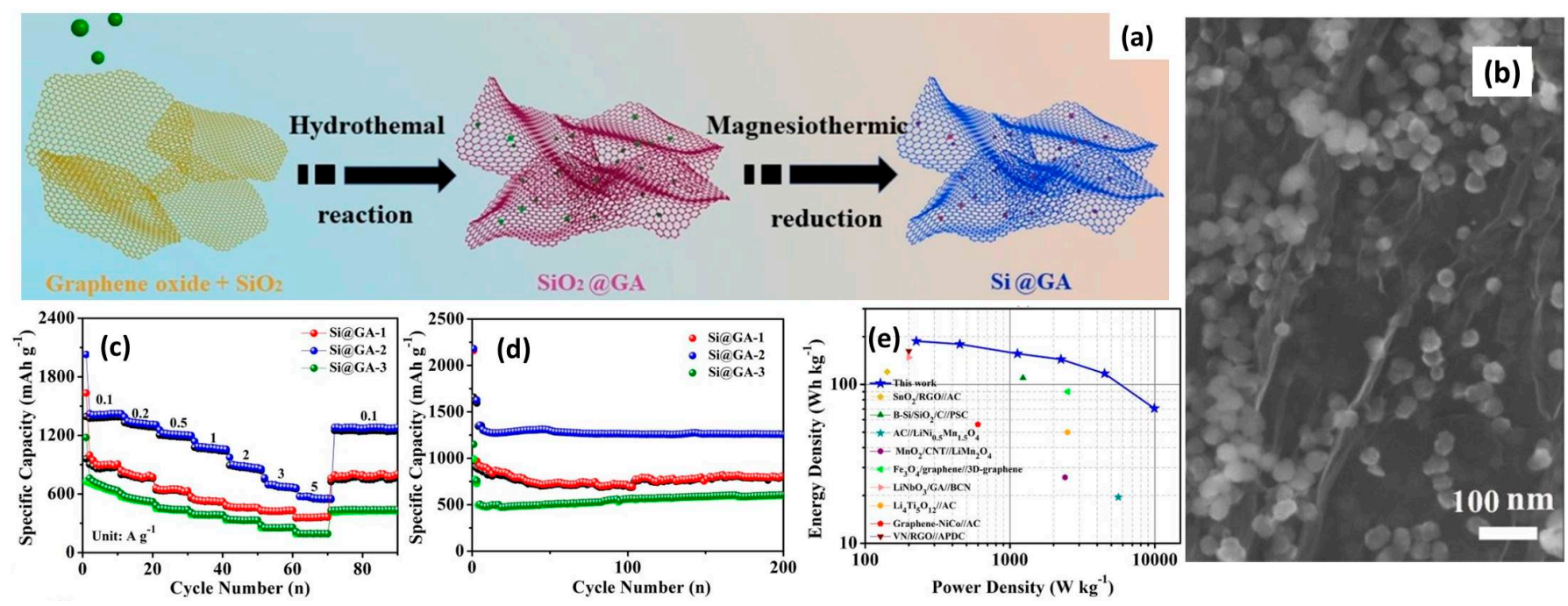

Figure 12. (a) Schematic illustration of preparation procedure for Si@GA anode; (b) SEM image of Si@GA-2 composite; (c) rate capability and (d) cycling performance of Si@GA composites; (e) Ragone plot for Si@GA//BCNNTs LIC compared with previous reports. Reproduced with permission from [134]. Copyright 2020, Royal Society of Chemistry. 
Table 4. Graphene/alloying-type anode materials and their LICs performance.

\begin{tabular}{|c|c|c|c|c|c|c|}
\hline Anode Materials & $\begin{array}{l}\text { Capacity of Anode } \\
\quad\left(\mathrm{mAh} \mathrm{g}^{-1}\right)\end{array}$ & $\begin{array}{l}\text { Cell Voltage } \\
\text { (V) }\end{array}$ & $\begin{array}{l}\text { Maximum } \\
\text { Energy Density } \\
\left(\mathrm{Wh} \mathrm{kg}^{-1}\right)\end{array}$ & $\begin{array}{c}\text { Maximum Power } \\
\text { Density }\left(\mathrm{kW} \mathrm{kg}^{-1}\right)\end{array}$ & Cycling Stability & Reference \\
\hline Si@GA & 1618.8 & $0-4.5$ & 197.3 & 11.2 & $82.4 \%$ after 10,000 & [134] \\
\hline SrGO-Sn & 292 & $2-3.8$ & 30 & 7.4 & $98 \%$ after 120,000 & [135] \\
\hline $\mathrm{SnO}_{2}-\mathrm{rGO}$ & 950 & $1.5-4.2$ & 186 & 10 & $70 \%$ after 5000 & [132] \\
\hline $\mathrm{SnO}_{2} @ \mathrm{C} @$ half-rGO & 879.6 & $0-4$ & 257 & 20 & $78.2 \%$ after 2000 & [136] \\
\hline $\mathrm{Ce}_{2} \mathrm{Sn}_{2} \mathrm{O}_{7} / \mathrm{RGO}$ & 814.6 & $0.01-3.8$ & 122.3 & 9.65 & $\sim 58 \%$ after 9000 & [137] \\
\hline $\mathrm{SnS}_{2} / \mathrm{RGO}$ & 1198 & $0-4.5$ & 149.5 & 35 & $90 \%$ after 10,000 & [133] \\
\hline
\end{tabular}

\section{Conclusions and Outlook}

Through integrating the advantages of LIBs and supercapacitors into one device, LICs are considered as the most promising systems to realize high energy density, high power density and outstanding cycling stability simultaneously. Nevertheless, the overall electrochemical performances of current LICs are still unsatisfactory. Especially, the high energy density could only be achieved at the cost of low power density due to the sluggish kinetics of the anode materials, not to mention their low electrical conductivity (for noncarbon anodes). Furthermore, the capacity and kinetics mismatch between anode and cathode further compromises the energy density. Besides, the structural degradation and sever volume variation of the anode during repeatedly charge/discharge process always results in a limited cycling life. Therefore, developing anode materials with high rate and stable structure is of great significance for advanced LICs. Under this circumstance, graphene with outstanding properties and flexible and stable 2D structure, has been found extensive applications in LICs either as active material or as an excellent substrate to form composites with other materials. In this review, we systematically summarized graphene-based anode materials for LICs and highlighted the important role of graphene. Based on the above discussions, it could be easily concluded that graphene makes a great contribution in improving the rate and cycling performances of the constructed battery-type electrodes and full cells.

However, there is still a long way to go prior to the commercial applications of LICs. The following several great challenges should be given more attention to develop advanced LICs, especially the graphene-based anode materials.

A feasible industrial production method of graphene for large-scale applications. Among the graphene preparation technologies, the modified Hummers method has the shortcomings of complex and tedious process, using hazardous reactants and generating heavy metal ions and other toxic materials while the mechanical exfoliation and chemical vapor deposition suffer from low yield and high cost. Thus, it is highly demanded to develop a facile, cost effective, green and large-scale production method to materialize the industrial-level application of graphene.

Advanced anodes with well-matched rate and cycling performance with cathodes. Currently, the rate capability and cycling stability of the reported anode materials, even compositing with graphene, cannot compete with those of cathodes due to the sluggish Faradaic reaction mechanism and structure degradation (i.e., volume change, side reactions). Therefore, regulating the porosity, nanostructure engineering and forming composite with high conductive materials are always adopted to enhance their electrochemical properties. According to the previous reports, intercalation-type and conversion-type anodes have been thoroughly investigated while the research of high-capacity alloying-type anodes is only limited to $\mathrm{Si} / \mathrm{Sn}$-based materials. Hence, other alloying-type materials (such as $\mathrm{P} / \mathrm{Ge} / \mathrm{Sb} / \mathrm{Bi}$-based compounds and their composites) are also promising battery-type electrodes. It must be noted that elaborate technologies should be used to enhance the conductivity and to buffer the volume variation of these materials. In addition, other emerging nanostructured materials such as MXene, phosphorene and graphdiyne should 
be given more attention as anodes due to their high conductivity, tunable layer distance and/or more exposed active sites.

Efficient and feasible pre-lithiation technology. The anodes of LICs usually consume a large amount of electrolyte to form a stable solid-electrolyte interface at the electrode surface during the first few cycles. This situation is more serious for graphene-based nanostructured anode materials because of their large SSA. Therefore, pre-lithiation is highly necessary for the anode to increase the operational voltage, energy and power densities, and cycling stability as well as reducing the irreversible capacity. Thus, so far, metallic lithium belt/powder, lithium metal oxides/nitrides, lithium salts are typically adopted to compensate the lithium loss and stabilize the anode. However, it is still a big challenge to realize facile, controllable and safe pre-lithiation, promoting researchers to develop novel technology.

Developing safe and stable electrolytes. Organic electrolytes are typically applied to ensure high working voltage. However, they suffer from safety risk at extreme conditions because of their flammable and volatile property. Additionally, they also face the challenge of decomposition, especially oxidation at high potential. Under this circumstance, ionic liquids are emerging as novel electrolytes and have been investigated in energy storage systems owing to their wide operation voltage, good conductivity, high safety, excellent thermal stability and non-inflammability. Recently, advanced aqueous electrolytes such as "water-in-salt" electrolyte also receive enormous interests because they combine the advantages of high voltage of non-aqueous ones and high safety of aqueous electrolytes.

The practical LICs are expected to integrate the features of high energy, high power and long cycling life into one system. However, the state-of-art of LICs could not realize these performances simultaneously due to the structural instability of electrode materials, the mismatched capacity and rate between cathode and anode. Recent reports of metal compounds with pseudocapacitive behavior exhibit excellent high-rate charge/discharge ability and long-term cycling stability through microstructure engineering and forming composite with high conductive materials, which might be a possible solution to the current dilemma of anodes. Two methods could be applied to further enhance the capacity of porous carbon cathode, such as designing a hierarchical structure with rational pore size distribution to increase the accessible SSA, and doping with heteroatom or forming composites with redox active materials to introduce pseudocapacitance. Recently, dualcarbon LICs (also known as all-carbon LICs), which are composed of carbon anode and cathode, have drawn intensive interests due to their low cost, abundant resources, and structural/chemical/electrochemical stability. More importantly, they also have the advantage of renewability with various biomass-based raw materials. However, nanostructured materials with large SSA and rich porosity usually suffer from low tap density, resulting in inferior volumetric energy and power densities. This situation is more serious for nanocarbon-based electrodes. Thus, the porosity and the taping density should be well balanced to obtain both high gravimetric and volumetric performances, especially for the nanocarbon-based materials.

Other systems of hybrid capacitors. Considering the limited and the uneven distribution of lithium resources in the crust, it is reasonable to design and fabricate $\mathrm{Na} / \mathrm{K}$-ion capacitors which have similar device configuration and working mechanism with LICs but abundant resources. Besides, other systems using multivalent ions as charge carriers (such as $\mathrm{Zn}^{2+}, \mathrm{Mg}^{2+}, \mathrm{Al}^{3+}$ ) are emerging as novel energy storage devices. Especially, Zn-based ion capacitors have drawn tremendous interests recently due to their merits of high safety, low cost and non-toxicity. More importantly, they are less sensitive to air and water so that aqueous electrolyte could be used.

In summary, LICs with the graphene-based anodes have gained tremendous progresses although they are still far from the ideal target of having comparable energy density with LIBs and power density and cycling life with SCs. Thus, more efforts should be devoted to developing high-rate and stable-cycling anodes and high-capacity cathodes, aiming to mitigate the performance gap between them. We believe that the drawbacks of 
current LICs will be overcome and the practical applications of LICs will be realized under the cooperation of the academic and industrial communities.

Author Contributions: Conceptualization, D.S., Y.Z. and W.Y.; Literature search, L.S. and C.L.; Figures, C.L. and Y.Y.; Writing-Original Draft Preparation, D.S. and L.S.; Writing-Review \& Editing, D.S., Y.Z. and W.Y. All authors have read and agreed to the published version of the manuscript.

Funding: This research was funded by the National Natural Science Foundation of China (NSFC, 21902071), Henan Provincial Key Research and Development Program (192102310202).

Institutional Review Board Statement: Not applicable.

Informed Consent Statement: Not applicable.

Data Availability Statement: Not applicable.

Conflicts of Interest: The authors declare no conflict of interest.

\section{References}

1. Liu, C.; Li, F.; Ma, L.-P.; Cheng, H.-M. Advanced Materials for Energy Storage. Adv. Mater. 2010, 22, E28-E62. [CrossRef]

2. Lu, L.; Han, X.; Li, J.; Hua, J.; Ouyang, M. A review on the key issues for lithium-ion battery management in electric vehicles. J. Power Sources 2013, 226, 272-288. [CrossRef]

3. Liu, G.; Li, M.; Wu, N.; Cui, L.; Huang, X.; Liu, X.; Zhao, Y.; Chen, H.; Yuan, W.; Bai, Y. Single-Crystalline Particles: An Effective Way to Ameliorate the Intragranular Cracking, Thermal Stability, and Capacity Fading of the $\mathrm{LiNi}_{0.6} \mathrm{Co}_{0.2} \mathrm{Mn}_{0.2} \mathrm{O}_{2}$ Electrodes. J. Electrochem. Soc. 2018, 165, A3040-A3047. [CrossRef]

4. Dunn, B.; Kamath, H.; Tarascon, J.M. Electrical Energy Storage for the Grid: A Battery of Choices. Science 2011, 334, 928-935. [CrossRef]

5. Simon, P.; Gogotsi, Y. Perspectives for electrochemical capacitors and related devices. Nat. Mater. 2020, 19, 1151-1163. [CrossRef] [PubMed]

6. Li, C.; Zhang, X.; Sun, C.; Wang, K.; Sun, X.; Ma, Y. Recent progress of graphene-based materials in lithium-ion capacitors. J. Phys. D Appl. Phys. 2019, 52, 143001. [CrossRef]

7. Liu, Y.; Zhu, Y.; Cui, Y. Challenges and opportunities towards fast-charging battery materials. Nat. Energy 2019, 4, 540-550. [CrossRef]

8. Wu, N.; Shen, J.; Sun, L.; Yuan, M.; Shao, Y.; Ma, J.; Liu, G.; Guo, D.; Liu, X.; He, Y.-B. Hierarchical N-doped graphene coated 1D cobalt oxide microrods for robust and fast lithium storage at elevated temperature. Electrochim. Acta 2019, 310, 70-77. [CrossRef]

9. Zhang, M.; Sun, Z.; Zhang, T.; Qin, B.; Sui, D.; Xie, Y.; Ma, Y.; Chen, Y. Porous asphalt/graphene composite for supercapacitors with high energy density at superior power density without added conducting materials. J. Mater. Chem. A 2017, 5, 21757-21764. [CrossRef]

10. Tie, D.; Huang, S.; Wang, J.; Ma, J.; Zhang, J.; Zhao, Y. Hybrid energy storage devices: Advanced electrode materials and matching principles. Energy Storage Mater. 2019, 21, 22-40. [CrossRef]

11. Zuo, W.; Li, R.; Zhou, C.; Li, Y.; Xia, J.; Liu, J. Battery-Supercapacitor Hybrid Devices: Recent Progress and Future Prospects. Adv. Sci. 2017, 4, 1600539. [CrossRef] [PubMed]

12. Ma, Y.; Chang, H.; Zhang, M.; Chen, Y. Graphene-Based Materials for Lithium-Ion Hybrid Supercapacitors. Adv. Mater. 2015, 27, 5296-5308. [CrossRef] [PubMed]

13. Jagadale, A.; Zhou, X.; Xiong, R.; Dubal, D.P.; Xu, J.; Yang, S. Lithium ion capacitors (LICs): Development of the materials. Energy Storage Mater. 2019, 19, 314-329. [CrossRef]

14. Zhang, T.; Zhang, F.; Zhang, L.; Lu, Y.; Zhang, Y.; Yang, X.; Ma, Y.; Huang, Y. High energy density Li-ion capacitor assembled with all graphene-based electrodes. Carbon 2015, 92, 106-118. [CrossRef]

15. Amatucci, G.G.; Badway, F.; Du Pasquier, A.; Zheng, T. An Asymmetric Hybrid Nonaqueous Energy Storage Cell. J. Electrochem. Soc. 2001, 148, A930. [CrossRef]

16. Li, G.; Yang, Z.; Yin, Z.; Guo, H.; Wang, Z.; Yan, G.; Liu, Y.; Li, L.; Wang, J. Non-aqueous dualcarbon lithiumion capacitors: A review. J. Mater. Chem. A 2019, 7, 15541-15563. [CrossRef]

17. Dubey, P.; Shrivastav, V.; Maheshwari, P.H.; Sundriyal, S. Recent advances in biomass derived activated carbon electrodes for hybrid electrochemical capacitor applications: Challenges and opportunities. Carbon 2020, 170, 1-29. [CrossRef]

18. Divya, M.L.; Natarajan, S.; Lee, Y.-S.; Aravindan, V. Achieving high-energy dual carbon Li-ion capacitors with unique low- and high-temperature performance from spent Li-ion batteries. J. Mater. Chem. A 2020, 8, 4950-4959. [CrossRef]

19. Lang, J.; Zhang, X.; Liu, B.; Wang, R.; Chen, J.; Yan, X. The roles of graphene in advanced Li-ion hybrid supercapacitors. J. Energy Chem. 2018, 27, 43-56. [CrossRef]

20. Wang, F.; Liu, Z.; Yuan, X.; Mo, J.; Li, C.; Fu, L.; Zhu, Y.; Wu, X.; Wu, Y. A quasi-solid-state Li-ion capacitor with high energy density based on $\mathrm{Li}_{3} \mathrm{VO}_{4}$ /carbon nanofibers and electrochemically-exfoliated graphene sheets. J. Mater. Chem. A 2017, 5, 14922-14929. [CrossRef] 
21. Li, B.; Dai, F.; Xiao, Q.; Yang, L.; Shen, J.; Zhang, C.; Cai, M. Activated Carbon from Biomass Transfer for High-Energy Density Lithium-Ion Supercapacitors. Adv. Energy Mater. 2016, 6, 1600802. [CrossRef]

22. Sennu, P.; Arun, N.; Madhavi, S.; Aravindan, V.; Lee, Y.-S. All carbon based high energy lithium-ion capacitors from biomass: The role of crystallinity. J. Power Sources 2019, 414, 96-102. [CrossRef]

23. Aref, A.R.; Chen, S.-W.; Rajagopalan, R.; Randall, C. Bimodal porous carbon cathode and prelithiated coalesced carbon onion anode for ultrahigh power energy efficient lithium ion capacitors. Carbon 2019, 152, 89-97. [CrossRef]

24. Cao, W.J.; Zheng, J.P. Li-ion capacitors with carbon cathode and hard carbon/stabilized lithium metal powder anode electrodes. J. Power Sources 2012, 213, 180-185. [CrossRef]

25. Zhang, M.; Dong, L.; Zhang, C.; Yin, F.; Peng, H.; Wang, G. Heterogeneous nucleation of $\mathrm{Li}_{3} \mathrm{VO}_{4}$ regulated in dense graphene aerogel for lithium ion capacitors. J. Power Sources 2020, 468, 228364. [CrossRef]

26. Fu, C.; Zhang, L.; Peng, J.; Wang, H.; Yan, H. Synthesis of $\mathrm{Li}_{4} \mathrm{Ti}_{5} \mathrm{O}_{12}$-reduced graphene oxide composite and its application for hybrid supercapacitors. Ionics 2016, 22, 1829-1836. [CrossRef]

27. Yang, C.; Lan, J.-L.; Ding, C.; Wang, F.; Siyal, S.H.; Yu, Y.; Yang, X. Three-dimensional hierarchical ternary aerogels of ultrafine TiO 2 nanoparticles@porous carbon nanofibers-reduced graphene oxide for high-performance lithium-ion capacitors. Electrochim. Acta 2019, 296, 790-798. [CrossRef]

28. Tian, M.; Liu, C.; Neale, Z.G.; Zheng, J.; Long, D.; Cao, G. Chemically Bonding NiFe-LDH Nanosheets on rGO for Superior Lithium-Ion Capacitors. ACS Appl. Mater. Interfaces 2019, 11, 35977-35986. [CrossRef] [PubMed]

29. Zhao, X.; Zhang, X.; Li, C.; Sun, X.; Liu, J.; Wang, K.; Ma, Y. High-Performance Lithium-Ion Capacitors Based on CoO-Graphene Composite Anode and Holey Carbon Nanolayer Cathode. ACS Sustain. Chem. Eng. 2019, 7, 11275-11283. [CrossRef]

30. Zhang, S.; Li, C.; Zhang, X.; Sun, X.; Wang, K.; Ma, Y. High Performance Lithium-Ion Hybrid Capacitors Employing Fe $\mathrm{F}_{3} \mathrm{O}_{4}-\mathrm{Graphene}$ Composite Anode and Activated Carbon Cathode. ACS Appl. Mater. Interfaces 2017, 9, 17136-17144. [CrossRef] [PubMed]

31. Dai, X.; Lei, S.; Liu, J.; Shang, Z.; Zhong, S.; Li, X. Promoting the energy density of lithium-ion capacitor by coupling the pore-size and nitrogen content in capacitive carbon cathode. J. Power Sources 2021, 498, 229912. [CrossRef]

32. Sun, F.; Gao, J.; Zhu, Y.; Pi, X.; Wang, L.; Liu, X.; Qin, Y. A high performance lithium ion capacitor achieved by the integration of a Sn-C anode and a biomass-derived microporous activated carbon cathode. Sci. Rep. 2017, 7, 40990. [CrossRef]

33. Han, P.; Xu, G.; Han, X.; Zhao, J.; Zhou, X.; Cui, G. Lithium Ion Capacitors in Organic Electrolyte System: Scientific Problems, Material Development, and Key Technologies. Adv. Energy Mater. 2018, 8, 1801243. [CrossRef]

34. Li, B.; Zheng, J.; Zhang, H.; Jin, L.; Yang, D.; Lv, H.; Shen, C.; Shellikeri, A.; Zheng, Y.; Gong, R.; et al. Electrode Materials, Electrolytes, and Challenges in Nonaqueous Lithium-Ion Capacitors. Adv. Mater. 2018, 30, 1705670. [CrossRef] [PubMed]

35. Wang, X.; Liu, L.; Niu, Z. Carbon-based materials for lithium-ion capacitors. Mater. Chem. Front. 2019, 3, 1265-1279. [CrossRef]

36. Kim, H.; Park, K.-Y.; Cho, M.-Y.; Kim, M.-H.; Hong, J.; Jung, S.-K.; Roh, K.C.; Kang, K. High-Performance Hybrid Supercapacitor Based on Graphene-Wrapped $\mathrm{Li}_{4} \mathrm{Ti}_{5} \mathrm{O}_{12}$ and Activated Carbon. ChemElectroChem 2014, 1, 125-130. [CrossRef]

37. Ma, Y.; Chen, Y. Three-dimensional graphene networks: Synthesis, properties and applications. Natl. Sci. Rev. 2014, 2, 40-53. [CrossRef]

38. Sui, D.; Xu, L.; Zhang, H.; Sun, Z.; Kan, B.; Ma, Y.; Chen, Y. A 3D cross-linked graphene-based honeycomb carbon composite with excellent confinement effect of organic cathode material for lithium-ion batteries. Carbon 2020, 157, 656-662. [CrossRef]

39. Ma, H.; Zhou, Q.; Wu, M.; Zhang, M.; Yao, B.; Gao, T.; Wang, H.; Li, C.; Sui, D.; Chen, Y.; et al. Tailoring the oxygenated groups of graphene hydrogels for high-performance supercapacitors with large areal mass loadings. J. Mater. Chem. A 2018, 6, 6587-6594. [CrossRef]

40. Sui, D.; Chang, M.; Wang, H.; Qian, H.; Yang, Y.; Li, S.; Zhang, Y.; Song, Y. A Brief Review of Catalytic Cathode Materials for $\mathrm{Na}-\mathrm{CO}_{2}$ Batteries. Catalysts 2021, 11, 603. [CrossRef]

41. Wang, Y.; Zhang, Q.; Jia, M.; Yang, D.; Wang, J.; Li, M.; Zhang, J.; Sun, Q.; Jia, Y. Porous graphene for high capacity lithium ion battery anode material. Appl. Surf. Sci. 2016, 363, 318-322. [CrossRef]

42. Jang, B.Z.; Liu, C.; Neff, D.; Yu, Z.; Wang, M.C.; Xiong, W.; Zhamu, A. Graphene Surface-Enabled Lithium Ion-Exchanging Cells: Next-Generation High-Power Energy Storage Devices. Nano Lett. 2011, 11, 3785-3791. [CrossRef] [PubMed]

43. Leng, K.; Zhang, F.; Zhang, L.; Zhang, T.; Wu, Y.; Lu, Y.; Huang, Y.; Chen, Y. Graphene-based Li-ion hybrid supercapacitors with ultrahigh performance. Nano Res. 2013, 6, 581-592. [CrossRef]

44. Yang, B.; Chen, J.; Liu, B.; Ding, Y.; Tang, Y.; Yan, X. One dimensional graphene nanoscroll-wrapped MnO nanoparticles for high-performance lithium ion hybrid capacitors. J. Mater. Chem. A 2021, 9, 6352-6360. [CrossRef]

45. Sivakkumar, S.R.; Nerkar, J.Y.; Pandolfo, A.G. Rate capability of graphite materials as negative electrodes in lithium-ion capacitors. Electrochim. Acta 2010, 55, 3330-3335. [CrossRef]

46. Ren, J.J.; Su, L.W.; Qin, X.; Yang, M.; Wei, J.P.; Zhou, Z.; Shen, P.W. Pre-lithiated graphene nanosheets as negative electrode materials for Li-ion capacitors with high power and energy density. J. Power Sources 2014, 264, 108-113. [CrossRef]

47. Sun, X.; Zhang, X.; Zhang, H.; Xu, N.; Wang, K.; Ma, Y. High performance lithium-ion hybrid capacitors with pre-lithiated hard carbon anodes and bifunctional cathode electrodes. J. Power Sources 2014, 270, 318-325. [CrossRef]

48. Zhang, J.; Liu, X.; Wang, J.; Shi, J.; Shi, Z. Different types of pre-lithiated hard carbon as negative electrode material for lithium-ion capacitors. Electrochim. Acta 2016, 187, 134-142. [CrossRef]

49. Wang, L.; Liu, Y.; Chong, C.; Wang, J.; Shi, Z.; Pan, J. Phenolic formaldehyde resin/graphene composites as lithium-ion batteries anode. Mater. Lett. 2016, 170, 217-220. [CrossRef] 
50. Yoo, E.; Kim, J.; Hosono, E.; Zhou, H.-S.; Kudo, T.; Honma, I. Large Reversible Li Storage of Graphene Nanosheet Families for Use in Rechargeable Lithium Ion Batteries. Nano Lett. 2008, 8, 2277-2282. [CrossRef]

51. Han, S.; Wu, D.; Li, S.; Zhang, F.; Feng, X. Graphene: A Two-Dimensional Platform for Lithium Storage. Small 2013, 9, 1173-1187. [CrossRef]

52. Wu, Z.-S.; Ren, W.; Xu, L.; Li, F.; Cheng, H.-M. Doped Graphene Sheets as Anode Materials with Superhigh Rate and Large Capacity for Lithium Ion Batteries. ACS Nano 2011, 5, 5463-5471. [CrossRef]

53. Ahn, W.; Lee, D.U.; Li, G.; Feng, K.; Wang, X.; Yu, A.; Lui, G.; Chen, Z. Highly Oriented Graphene Sponge Electrode for Ultra High Energy Density Lithium Ion Hybrid Capacitors. ACS Appl. Mater. Interfaces 2016, 8, 25297-25305. [CrossRef]

54. Sha, J.; Chu, X.; Xu, T.; Li, Y.; Tang, Y.; Ma, L.; Shi, C.; Liu, E.; Zhao, D.; He, C.; et al. Bi-functional modular graphene network with high rate and cycling performance. J. Power Sources 2021, 504, 230075. [CrossRef]

55. Li, Z.; Cao, L.; Chen, W.; Huang, Z.; Liu, H. Mesh-Like Carbon Nanosheets with High-Level Nitrogen Doping for High-Energy Dual-Carbon Lithium-Ion Capacitors. Small 2019, 15, 1805173. [CrossRef] [PubMed]

56. Wang, X.; Wang, Z.; Zhang, X.; Peng, H.; Xin, G.; Lu, C.; Zhong, Y.; Wang, G.; Zhang, Y. Nitrogen-Doped Defective Graphene Aerogel as Anode for all Graphene-Based Lithium Ion Capacitor. ChemistrySelect 2017, 2, 8436-8445. [CrossRef]

57. Li, C.; Zhang, X.; Wang, K.; Sun, X.; Liu, G.; Li, J.; Tian, H.; Li, J.; Ma, Y. Scalable Self-Propagating High-Temperature Synthesis of Graphene for Supercapacitors with Superior Power Density and Cyclic Stability. Adv. Mater. 2017, 29, 1604690. [CrossRef] [PubMed]

58. Li, C.; Zhang, X.; Wang, K.; Sun, X.; Ma, Y. High-power and long-life lithium-ion capacitors constructed from N-doped hierarchical carbon nanolayer cathode and mesoporous graphene anode. Carbon 2018, 140, 237-248. [CrossRef]

59. Li, C.; Zhang, X.; Wang, K.; Sun, X.; Xu, Y.; Su, F.; Chen, C.-M.; Liu, F.; Wu, Z.-S.; Ma, Y. Nitrogen-enriched graphene framework from a large-scale magnesiothermic conversion of $\mathrm{CO}_{2}$ with synergistic kinetics for high-power lithium-ion capacitors. NPG Asia Mater. 2021, 13, 59. [CrossRef]

60. Zhang, L.; Zhang, F.; Yang, X.; Long, G.; Wu, Y.; Zhang, T.; Leng, K.; Huang, Y.; Ma, Y.; Yu, A.; et al. Porous 3D graphene-based bulk materials with exceptional high surface area and excellent conductivity for supercapacitors. Sci. Rep. 2013, 3, 1408. [CrossRef]

61. Yang, Y.; Lin, Q.; Ding, B.; Wang, J.; Malgras, V.; Jiang, J.; Li, Z.; Chen, S.; Dou, H.; Alshehri, S.M.; et al. Lithium-ion capacitor based on nanoarchitectured polydopamine/graphene composite anode and porous graphene cathode. Carbon 2020, 167, 627-633. [CrossRef]

62. Sui, D.; Wu, M.; Liu, Y.; Yang, Y.; Zhang, H.; Ma, Y.; Zhang, L.; Chen, Y. High performance Li-ion capacitor fabricated with dual graphene-based materials. Nanotechnology 2020, 32, 015403. [CrossRef] [PubMed]

63. Tjandra, R.; Liu, W.; Lim, L.; Yu, A. Melamine based, n-doped carbon/reduced graphene oxide composite foam for Li-ion Hybrid Supercapacitors. Carbon 2018, 129, 152-158. [CrossRef]

64. Wang, R.; Zhao, Q.; Zheng, W.; Ren, Z.; Hu, X.; Li, J.; Lu, L.; Hu, N.; Molenda, J.; Liu, X.; et al. Achieving high energy density in a 4.5 V all nitrogen-doped graphene based lithium-ion capacitor. J. Mater. Chem. A 2019, 7, 19909-19921. [CrossRef]

65. Gómez-Urbano, J.L.; Moreno-Fernández, G.; Arnaiz, M.; Ajuria, J.; Rojo, T.; Carriazo, D. Graphene-coffee waste derived carbon composites as electrodes for optimized lithium ion capacitors. Carbon 2020, 162, 273-282. [CrossRef]

66. Ajuria, J.; Zarrabeitia, M.; Arnaiz, M.; Urra, O.; Rojo, T.; Goikolea, E. Graphene as Vehicle for Ultrafast Lithium Ion Capacitor Development Based on Recycled Olive Pit Derived Carbons. J. Electrochem. Soc. 2019, 166, A2840-A2848. [CrossRef]

67. An, Y.; Liu, T.; Li, C.; Zhang, X.; Hu, T.; Sun, X.; Wang, K.; Wang, C.; Ma, Y. A general route for the mass production of graphene-enhanced carbon composites toward practical pouch lithium-ion capacitors. J. Mater. Chem. A 2021, 9, 15654-15664. [CrossRef]

68. Wang, Y.; Wu, Y.; Huang, Y.; Zhang, F.; Yang, X.; Ma, Y.; Chen, Y. Preventing Graphene Sheets from Restacking for HighCapacitance Performance. J. Phys. Chem. C 2011, 115, 23192-23197. [CrossRef]

69. Sun, Y.; Tang, J.; Qin, F.; Yuan, J.; Zhang, K.; Li, J.; Zhu, D.-M.; Qin, L.-C. Hybrid lithium-ion capacitors with asymmetric graphene electrodes. J. Mater. Chem. A 2017, 5, 13601-13609. [CrossRef]

70. Adelowo, E.; Baboukani, A.R.; Chen, C.; Wang, C. Electrostatically Sprayed Reduced Graphene Oxide-Carbon Nanotubes Electrodes for Lithium-Ion Capacitors. C 2018, 4, 31. [CrossRef]

71. Phattharasupakun, N.; Wutthiprom, J.; Suktha, P.; Ma, N.; Sawangphruk, M. Enhancing the Charge Storage Capacity of LithiumIon Capacitors Using Nitrogen-Doped Reduced Graphene Oxide Aerogel as a Negative Electrode: A Hydrodynamic Rotating Disk Electrode Investigation. J. Electrochem. Soc. 2018, 165, A609-A617. [CrossRef]

72. Zhao, B.; Ran, R.; Liu, M.; Shao, Z. A comprehensive review of $\mathrm{Li}_{4} \mathrm{Ti}_{5} \mathrm{O}_{12}$-based electrodes for lithium-ion batteries: The latest advancements and future perspectives. Mater. Sci. Eng. R Rep. 2015, 98, 1-71. [CrossRef]

73. Ding, J.; Hu, W.; Paek, E.; Mitlin, D. Review of Hybrid Ion Capacitors: From Aqueous to Lithium to Sodium. Chem. Rev. 2018, 118, 6457-6498. [CrossRef] [PubMed]

74. Jung, H.-G.; Venugopal, N.; Scrosati, B.; Sun, Y.-K. A high energy and power density hybrid supercapacitor based on an advanced carbon-coated $\mathrm{Li}_{4} \mathrm{Ti}_{5} \mathrm{O}_{12}$ electrode. J. Power Sources 2013, 221, 266-271. [CrossRef]

75. Zhang, X.; Lu, C.; Peng, H.; Wang, X.; Zhang, Y.; Wang, Z.; Zhong, Y.; Wang, G. Influence of sintering temperature and graphene additives on the electrochemical performance of porous $\mathrm{Li}_{4} \mathrm{Ti}_{5} \mathrm{O}_{12}$ anode for lithium ion capacitor. Electrochim. Acta 2017, 246, 1237-1247. [CrossRef] 
76. Lu, C.; Wang, X.; Zhang, X.; Peng, H.; Zhang, Y.; Wang, G.; Wang, Z.; Cao, G.; Umirov, N.; Bakenov, Z. Effect of graphene nanosheets on electrochemical performance of $\mathrm{Li}_{4} \mathrm{Ti}_{5} \mathrm{O}_{12}$ in lithium-ion capacitors. Ceram. Int. 2017, 43, 6554-6562. [CrossRef]

77. Wang, G.; Lu, C.; Zhang, X.; Wan, B.; Liu, H.; Xia, M.; Gou, H.; Xin, G.; Lian, J.; Zhang, Y. Toward ultrafast lithium ion capacitors: A novel atomic layer deposition seeded preparation of $\mathrm{Li}_{4} \mathrm{Ti}_{5} \mathrm{O}_{12}$ /graphene anode. Nano Energy 2017, 36, 46-57. [CrossRef]

78. Jeong, J.H.; Lee, G.-W.; Kim, Y.H.; Choi, Y.J.; Roh, K.C.; Kim, K.-B. A holey graphene-based hybrid supercapacitor. Chem. Eng. J. 2019, 378, 122126. [CrossRef]

79. Wu, N.; Qiao, X.; Shen, J.; Liu, G.; Sun, T.; Wu, H.; Hou, H.; Liu, X.; Zhang, Y.; Ji, X. Anatase inverse opal TiO2-x@N-doped C induced the dominant pseudocapacitive effect for durable and fast lithium/sodium storage. Electrochim. Acta 2019, 299, 540-548. [CrossRef]

80. Chen, J.; Yang, B.; Liu, B.; Lang, J.; Yan, X. Recent advances in anode materials for sodium—And potassium-ion hybrid capacitors. Curr. Opin. Electrochem. 2019, 18, 1-8. [CrossRef]

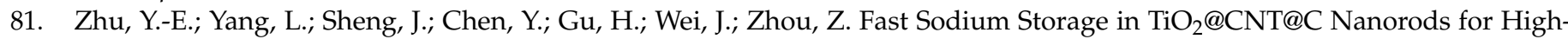
Performance Na-Ion Capacitors. Adv. Energy Mater. 2017, 7, 1701222. [CrossRef]

82. Kim, H.-K.; Mhamane, D.; Kim, M.-S.; Roh, H.-K.; Aravindan, V.; Madhavi, S.; Roh, K.C.; Kim, K.-B. TiO 2 -reduced graphene oxide nanocomposites by microwave-assisted forced hydrolysis as excellent insertion anode for Li-ion battery and capacitor. J. Power Sources 2016, 327, 171-177. [CrossRef]

83. Wang, J.; Li, J.; He, X.; Zhang, X.; Yan, B.; Hou, X.; Du, L.; Placke, T.; Winter, M.; Li, J. A three-dimensional TiO ${ }_{2}-\mathrm{Graphene}^{-}$ architecture with superior $\mathrm{Li}$ ion and $\mathrm{Na}$ ion storage performance. J. Power Sources 2020, 461, 228129. [CrossRef]

84. Auxilia, F.M.; Jang, J.; Jang, K.; Song, H.; Ham, M.-H. Au@ $\mathrm{TiO}_{2} /$ reduced graphene oxide nanocomposites for lithium-ion capacitors. Chem. Eng. J. 2019, 362, 136-143. [CrossRef]

85. Zhu, G.; Ma, L.; Lin, H.; Zhao, P.; Wang, L.; Hu, Y.; Chen, R.; Chen, T.; Wang, Y.; Tie, Z.; et al. High-performance Li-ion capacitor based on black- $\mathrm{TiO}_{2-\mathrm{x}} /$ graphene aerogel anode and biomass-derived microporous carbon cathode. Nano Res. 2019, 12, 1713-1719. [CrossRef]

86. Wang, H.; Zhu, C.; Chao, D.; Yan, Q.; Fan, H.J. Nonaqueous Hybrid Lithium-Ion and Sodium-Ion Capacitors. Adv. Mater. 2017, 29, 1702093. [CrossRef] [PubMed]

87. Guo, D.; Yang, M.; Zhang, L.; Li, Y.; Wang, J.; Liu, G.; Wu, N.; Kim, J.-K.; Liu, X. Cr $\mathrm{O}_{3}$ nanosheet/carbon cloth anode with strong interaction and fast charge transfer for pseudocapacitive energy storage in lithium-ion batteries. RSC Adv. 2019, 9, 33446-33453 [CrossRef]

88. Liu, G.; Xu, L.; Li, Y.; Guo, D.; Wu, N.; Yuan, C.; Qin, A.; Cao, A.; Liu, X. Metal-organic frameworks derived anatase/rutile heterostructures with enhanced reaction kinetics for lithium and sodium storage. Chem. Eng. J. 2021, 430, 132689. [CrossRef]

89. Li, D.; Shi, J.; Liu, H.; Liu, C.; Dong, G.; Zhang, H.; Yang, Y.; Lu, G.; Wang, H. T- $\mathrm{Nb}_{2} \mathrm{O}_{5}$ embedded carbon nanosheets with superior reversibility and rate capability as an anode for high energy Li-ion capacitors. Sustain. Energy Fuels 2019, 3, $1055-1065$. [CrossRef]

90. Augustyn, V.; Come, J.; Lowe, M.A.; Kim, J.W.; Taberna, P.-L.; Tolbert, S.H.; Abruña, H.D.; Simon, P.; Dunn, B. High-rate electrochemical energy storage through $\mathrm{Li}^{+}$intercalation pseudocapacitance. Nat. Mater. 2013, 12, 518-522. [CrossRef]

91. Kim, J.W.; Augustyn, V.; Dunn, B. The Effect of Crystallinity on the Rapid Pseudocapacitive Response of $\mathrm{Nb}_{2} \mathrm{O}_{5}$. Adv. Energy Mater. 2012, 2, 141-148. [CrossRef]

92. Kong, L.; Liu, X.; Wei, J.; Wang, S.; Xu, B.B.; Long, D.; Chen, F. T-Nb $2 \mathrm{O}_{5}$ nanoparticle enabled pseudocapacitance with fast Li-ion intercalation. Nanoscale 2018, 10, 14165-14170. [CrossRef]

93. Wang, L.P.; Yu, L.; Satish, R.; Zhu, J.; Yan, Q.; Srinivasan, M.; Xu, Z. High-performance hybrid electrochemical capacitor with binder-free $\mathrm{Nb}_{2} \mathrm{O}_{5} @$ graphene. RSC Adv. 2014, 4, 37389-37394. [CrossRef]

94. Jiao, X.; Hao, Q.; Xia, X.; Wu, Z.; Lei, W. Metal organic framework derived $\mathrm{Nb}_{2} \mathrm{O}_{5} @ \mathrm{C}$ nanoparticles grown on reduced graphene oxide for high-energy lithium ion capacitors. Chem. Commun. 2019, 55, 2692-2695. [CrossRef] [PubMed]

95. Lu, X.; Jian, Z.; Fang, Z.; Gu, L.; Hu, Y.-S.; Chen, W.; Wang, Z.; Chen, L. Atomic-scale investigation on lithium storage mechanism in $\mathrm{TiNb}_{2} \mathrm{O}_{7}$. Energy Environ. Sci. 2011, 4, 2638-2644. [CrossRef]

96. Song, H.; Kim, Y.-T. A Mo-doped $\mathrm{TiNb}_{2} \mathrm{O}_{7}$ anode for lithium-ion batteries with high rate capability due to charge redistribution. Chem. Commun. 2015, 51, 9849-9852. [CrossRef] [PubMed]

97. Wang, X.; Shen, G. Intercalation pseudo-capacitive $\mathrm{TiNb}_{2} \mathrm{O}_{7} @$ carbon electrode for high-performance lithium ion hybrid electrochemical supercapacitors with ultrahigh energy density. Nano Energy 2015, 15, 104-115. [CrossRef]

98. Jiao, X.; Hao, Q.; Xia, X.; Yao, D.; Ouyang, Y.; Lei, W. Boosting long-cycle-life energy storage with holey graphene supported $\mathrm{TiNb}_{2} \mathrm{O}_{7}$ network nanostructure for lithium ion hybrid supercapacitors. J. Power Sources 2018, 403, 66-75. [CrossRef]

99. Li, S.; Chen, J.; Gong, X.; Wang, J.; Lee, P.S. Holey graphene-wrapped porous $\mathrm{TiNb}_{24} \mathrm{O}_{62}$ microparticles as high-performance intercalation pseudocapacitive anode materials for lithium-ion capacitors. NPG Asia Mater. 2018, 10, 406-416. [CrossRef]

100. Liu, A.; Zhang, H.; Xing, C.; Wang, Y.; Zhang, J.; Zhang, X.; Zhang, S. Intensified Energy Storage in High-Voltage Nanohybrid Supercapacitors via the Efficient Coupling between $\mathrm{TiNb}_{2} \mathrm{O}_{7} /$ Holey-rGO Nanoarchitectures and Ionic Liquid-Based Electrolytes. ACS Appl. Mater. Interfaces 2021, 13, 21349-21361. [CrossRef]

101. Zhao, Y.; Zhang, H.; Liu, A.; Jiao, Y.; Shim, J.-J.; Zhang, S. Fabrication of nanoarchitectured $\mathrm{TiO}_{2}(\mathrm{~B}) @ \mathrm{C} / \mathrm{rGO}$ electrode for $4 \mathrm{~V}$ quasi-solid-state nanohybrid supercapacitors. Electrochim. Acta 2017, 258, 343-352. [CrossRef] 
102. Zhu, W.; El-Khodary, S.A.; Li, S.; Zou, B.; Kang, R.; Li, G.; Ng, D.H.L.; Liu, X.; Qiu, J.; Zhao, Y.; et al. Roselle-like Zn 2 Ti $3 \mathrm{O}_{8} / \mathrm{rGO}$ nanocomposite as anode for lithium ion capacitor. Chem. Eng. J. 2020, 385, 123881. [CrossRef]

103. Li, S.; Shadike, Z.; Kwon, G.; Yang, X.-Q.; Lee, J.H.; Hwang, S. Asymmetric Reaction Pathways of Conversion-Type Electrodes for Lithium-Ion Batteries. Chem. Mater. 2021, 33, 3515-3523. [CrossRef]

104. Zhang, F.; Zhang, T.; Yang, X.; Zhang, L.; Leng, K.; Huang, Y.; Chen, Y. A high-performance supercapacitor-battery hybrid energy storage device based on graphene-enhanced electrode materials with ultrahigh energy density. Energy Environ. Sci. 2013, 6, 1623-1632. [CrossRef]

105. Huang, J.-L.; Fan, L.-Q.; Gu, Y.; Geng, C.-L.; Luo, H.; Huang, Y.-F.; Lin, J.-M.; Wu, J.-H. One-step solvothermal synthesis of high-capacity $\mathrm{Fe}_{3} \mathrm{O}_{4}$ /reduced graphene oxide composite for use in Li-ion capacitor. J. Alloy. Compd. 2019, 788, 1119-1126. [CrossRef]

106. Kim, H.-K.; Aravindan, V.; Roh, M.H.-K.; Lee, K.; Jung, M.-H.; Madhavi, S.; Roh, K.C.; Kim, K.-B. Exploring High-Energy Li-I(r)on Batteries and Capacitors with Conversion-Type $\mathrm{Fe}_{3} \mathrm{O}_{4}-\mathrm{rGO}$ as the Negative Electrode. ChemElectroChem 2017, 4, 2626-2633. [CrossRef]

107. Liu, C.; Ren, Q.-Q.; Zhang, S.-W.; Yin, B.-S.; Que, L.-F.; Zhao, L.; Sui, X.-L.; Yu, F.-D.; Li, X.; Gu, D.-M.; et al. High energy and power lithium-ion capacitors based on $\mathrm{Mn}_{3} \mathrm{O}_{4} / 3 \mathrm{D}$-graphene as anode and activated polyaniline-derived carbon nanorods as cathode. Chem. Eng. J. 2019, 370, 1485-1492. [CrossRef]

108. Jiang, S.; Yun, S.; Cao, H.; Zhang, Z.; Feng, H.; Chen, H. Porous carbon matrix-encapsulated MnO in situ derived from metal-organic frameworks as advanced anode materials for Li-ion capacitors. Sci. China Mater. 2021. [CrossRef]

109. Ulaganathan, M.; Aravindan, V.; Ling, W.C.; Yan, Q.; Madhavi, S. High energy Li-ion capacitors with conversion type $\mathrm{Mn}_{3} \mathrm{O}_{4}$ particulates anchored to few layer graphene as the negative electrode. J. Mater. Chem. A 2016, 4, 15134-15139. [CrossRef]

110. Yang, M.; Zhong, Y.; Ren, J.; Zhou, X.; Wei, J.; Zhou, Z. Fabrication of High-Power Li-Ion Hybrid Supercapacitors by Enhancing the Exterior Surface Charge Storage. Adv. Energy Mater. 2015, 5, 1500550. [CrossRef]

111. Han, P.; Ma, W.; Pang, S.; Kong, Q.; Yao, J.; Bi, C.; Cui, G. Graphene decorated with molybdenum dioxide nanoparticles for use in high energy lithium ion capacitors with an organic electrolyte. J. Mater. Chem. A 2013, 1, 5949-5954. [CrossRef]

112. Liu, W.; Li, J.; Feng, K.; Sy, A.; Liu, Y.; Lim, L.; Lui, G.; Tjandra, R.; Rasenthiram, L.; Chiu, G.; et al. Advanced Li-Ion Hybrid Supercapacitors Based on 3D Graphene-Foam Composites. ACS Appl. Mater. Interfaces 2016, 8, 25941-25953. [CrossRef]

113. Ock, I.W.; Lee, J.; Kang, J.K. Metal-Organic Framework-Derived Anode and Polyaniline Chain Networked Cathode with Mesoporous and Conductive Pathways for High Energy Density, Ultrafast Rechargeable, and Long-Life Hybrid Capacitors. Adv. Energy Mater. 2020, 10, 2001851. [CrossRef]

114. Liu, C.; Bai, Y.; Zhao, Y.; Yao, H.; Pang, H. MoS 2 /graphene composites: Fabrication and electrochemical energy storage. Energy Storage Mater. 2020, 33, 470-502. [CrossRef]

115. Wang, R.; Jin, D.; Zhang, Y.; Wang, S.; Lang, J.; Yan, X.; Zhang, L. Engineering metal organic framework derived 3D nanostructures for high performance hybrid supercapacitors. J. Mater. Chem. A 2017, 5, 292-302. [CrossRef]

116. Benavente, E.; Santa Ana, M.A.; Mendizábal, F.; González, G. Intercalation chemistry of molybdenum disulfide. Coord. Chem. Rev. 2002, 224, 87-109. [CrossRef]

117. Fang, X.; Hua, C.; Guo, X.; Hu, Y.; Wang, Z.; Gao, X.; Wu, F.; Wang, J.; Chen, L. Lithium storage in commercial MoS 2 in different potential ranges. Electrochim. Acta 2012, 81, 155-160. [CrossRef]

118. Kong, D.; He, H.; Song, Q.; Wang, B.; Lv, W.; Yang, Q.-H.; Zhi, L. Rational design of MoS $_{2} @$ graphene nanocables: Towards high performance electrode materials for lithium ion batteries. Energy Environ. Sci. 2014, 7, 3320-3325. [CrossRef]

119. Zhang, F.; Tang, Y.; Liu, H.; Ji, H.; Jiang, C.; Zhang, J.; Zhang, X.; Lee, C.-S. Uniform Incorporation of Flocculent Molybdenum Disulfide Nanostructure into Three-Dimensional Porous Graphene as an Anode for High-Performance Lithium Ion Batteries and Hybrid Supercapacitors. ACS Appl. Mater. Interfaces 2016, 8, 4691-4699. [CrossRef]

120. Wang, R.; Wang, S.; Jin, D.; Zhang, Y.; Cai, Y.; Ma, J.; Zhang, L. Engineering layer structure of MoS 2 -graphene composites with robust and fast lithium storage for high-performance Li-ion capacitors. Energy Storage Mater. 2017, 9, 195-205. [CrossRef]

121. Sun, Q.; Fu, Z.-W. Vanadium nitride as a novel thin film anode material for rechargeable lithium batteries. Electrochim. Acta 2008, 54, 403-409. [CrossRef]

122. Wang, R.; Lang, J.; Zhang, P.; Lin, Z.; Yan, X. Fast and Large Lithium Storage in 3D Porous VN Nanowires-Graphene Composite as a Superior Anode Toward High-Performance Hybrid Supercapacitors. Adv. Funct. Mater. 2015, 25, 2270-2278. [CrossRef]

123. Yang, C.; Sun, M.; Zhang, L.; Liu, P.; Wang, P.; Lu, H. ZnFe ${ }_{2} \mathrm{O}_{4} @$ Carbon Core-Shell Nanoparticles Encapsulated in Reduced Graphene Oxide for High-Performance Li-Ion Hybrid Supercapacitors. ACS Appl. Mater. Interfaces 2019, 11, 14713-14721. [CrossRef] [PubMed]

124. Kim, E.; Kim, H.; Park, B.-J.; Han, Y.-H.; Park, J.H.; Cho, J.; Lee, S.-S.; Son, J.G. Etching-Assisted Crumpled Graphene Wrapped Spiky Iron Oxide Particles for High-Performance Li-Ion Hybrid Supercapacitor. Small 2018, 14, 1704209. [CrossRef]

125. Zuo, X.; Zhu, J.; Müller-Buschbaum, P.; Cheng, Y.-J. Silicon based lithium-ion battery anodes: A chronicle perspective review. Nano Energy 2017, 31, 113-143. [CrossRef]

126. Ying, H.; Han, W.-Q. Metallic Sn-Based Anode Materials: Application in High-Performance Lithium-Ion and Sodium-Ion Batteries. Adv. Sci. 2017, 4, 1700298. [CrossRef]

127. Zhang, M.; Sun, Z.; Zhang, T.; Sui, D.; Ma, Y.; Chen, Y. Excellent cycling stability with high $\mathrm{SnO}_{2}$ loading on a three-dimensional graphene network for lithium ion batteries. Carbon 2016, 102, 32-38. [CrossRef]

128. Sui, D.; Xie, Y.; Zhao, W.; Zhang, H.; Zhou, Y.; Qin, X.; Ma, Y.; Yang, Y.; Chen, Y. A high-performance ternary Si composite anode material with crystal graphite core and amorphous carbon shell. J. Power Sources 2018, 384, 328-333. [CrossRef] 
129. An, Y.-B.; Chen, S.; Zou, M.-M.; Geng, L.-B.; Sun, X.-Z.; Zhang, X.; Wang, K.; Ma, Y.-W. Improving anode performances of lithium-ion capacitors employing carbon-Si composites. Rare Met. 2019, 38, 1113-1123. [CrossRef]

130. Shao, R.; Niu, J.; Zhu, F.; Dou, M.; Zhang, Z.; Wang, F. A facile and versatile strategy towards high-performance Si anodes for Li-ion capacitors: Concomitant conductive network construction and dual-interfacial engineering. Nano Energy 2019, 63, 103824. [CrossRef]

131. Sun, X.; Geng, L.; Yi, S.; Li, C.; An, Y.; Zhang, X.; Zhang, X.; Wang, K.; Ma, Y. Effects of carbon black on the electrochemical performances of $\mathrm{SiO}_{\mathrm{x}}$ anode for lithium-ion capacitors. J. Power Sources 2021, 499, 229936. [CrossRef]

132. Ajuria, J.; Arnaiz, M.; Botas, C.; Carriazo, D.; Mysyk, R.; Rojo, T.; Talyzin, A.V.; Goikolea, E. Graphene-based lithium ion capacitor with high gravimetric energy and power densities. J. Power Sources 2017, 363, 422-427. [CrossRef]

133. Hao, Y.; Wang, S.; Shao, Y.; Wu, Y.; Miao, S. High-Energy Density Li-Ion Capacitor with Layered SnS 2 /Reduced Graphene Oxide Anode and BCN Nanosheet Cathode. Adv. Energy Mater. 2020, 10, 1902836. [CrossRef]

134. Jiang, H.; Wang, S.; Shi, D.; Chen, F.; Shao, Y.; Wu, Y.; Hao, X. Lithium-ion capacitor with improved energy density via perfect matching silicon@3D graphene aerogel anode and BCNNTs cathode. J. Mater. Chem. A 2021, 9, 1134-1142. [CrossRef]

135. Ahn, S.; Haniu, Y.; Nara, H.; Momma, T.; Sugimoto, W.; Osaka, T. Synthesis of Stacked Graphene-Sn Composite as a HighPerformance Anode for Lithium-Ion Capacitors. J. Electrochem. Soc. 2020, 167, 040519. [CrossRef]

136. Zhu, C.; Chen, Z.; Zhu, S.; Li, Y.; Pan, H.; Meng, X.; Imtiaz, M.; Zhang, D. Construction of SnO ${ }_{2}-G^{-}$raphene Composite with Half-Supported Cluster Structure as Anode toward Superior Lithium Storage Properties. Sci. Rep. 2017, 7, 3276. [CrossRef] [PubMed]

137. Wu, Q.; Liu, Y.; Wang, H.-G.; Hou, J.; Li, Y.; Duan, Q. Graphene encapsulated metallic state $\mathrm{Ce}_{2} \mathrm{Sn}_{2} \mathrm{O}_{7}$ as a novel anode material for superior lithium-ion batteries and capacitors. J. Mater. Chem. A 2020, 8, 5517-5524. [CrossRef] 